\title{
¿Sobran o faltan doctores?
}

\author{
Jesús M. DE Miguel \\ Universidad de Barcelona \\ jesusdemiguel@ub.edu \\ Bernabe Sarabia Heydrich \\ Universidad Pública de Navarra \\ bernabe.sarabia@educ.mec.es \\ Elizabeth G. Vaquera \\ The University of Pennsylvania \\ vaquera@sas.upenn.edu \\ HaIzAM AmIRAH \\ Real Instituto Elcano de Estudios Internacionales y Estratégicos \\ amirahfh@georgetown.edu
}

Para Robert K. Merton, In Memoriam.

Datos y empiria sirven para evaluar los problemas de los/as investigadores en España ${ }^{1}$. El presente artículo analiza las necesidades de doctores (graduados de tercer ciclo universitario) en España en la actualidad, estudiando la evolución seguida en la última década, y comparando con otros países especialmente Estados Unidos y la Unión Europea ${ }^{2}$. En España, las tasas de estudiantes de doctorado y de producción de doctores son elevadas, al contrario de lo que se espera según los indicadores de I+D. La proporción de extranjeros que se matriculan en doctorado es alta y creciente. La plétora se explica porque todas las universidades españolas - públicas y privadas- producen doctores y no sólo las mejores universidades; además hay programas de doctorado en la mayoría de los Departamentos. El sistema universitario se autorregula, aunque lo hace de forma imperfecta. Los programas de doctorado de las universidades españolas son fundamentalmente un sistema de formación de personal docente propio. La proporción de estudiantes que empiezan el doctorado y no lo terminan es elevada: unas tres cuartas partes. La bolsa de doctores sin posibilidades de integrarse en el sistema universitario como

${ }^{1}$ El presente artículo sigue con alguna de las hipótesis planteadas en DE MIGUEL, PONCE DE LEÓN y ECHAVARREN (1999) en Empiria.

${ }^{2}$ Agradecemos los comentarios y críticas de Jordi Cornadó (Universidad Politécnica de Cataluña), Jordi D. MARTIN y Jara SÁnChEZ BENNASAR (Universidad de Barcelona), así como de varios colegas del Departamento de Sociología de la Universidad de Barcelona. 
docentes o investigadores es cada vez mayor. Las diferencias regionales son además enormes.

La formación de doctores -es decir de investigadores- es una de las tareas más complicadas de la Universidad. El Proceso de Bolonia que se inicia en 1999 apenas lo ha resuelto para Europa (De Miguel, 2004). La Universidad española contrata al $55 \%$ de los/as investigadores. La baja participación del sector privado en la investigación es una de las características negativas del sistema de I+D español. Tras la tesis doctoral la mayoría de nuevos doctores no siguen realizando investigación, con lo que apenas se cuenta con investigadores avanzando el conocimiento y la tecnología. El retraso español en $I+D$ es llamativo. La mayoría de analistas coinciden en que los recursos deberían multiplicarse por dos o por tres. Con el incremento actual de recursos no se está consiguiendo reducir la distancia respecto a los países más avanzados del mundo. Las diferencias con Estados Unidos y Japón son cada vez mayores. Las universidades españolas producen doctores fundamentalmente para sus propias necesidades de profesorado, y por lo tanto la movilidad de doctores es mínima. Los datos que publica el Instituto Nacional de Estadística y el Ministerio de Educación (MECD) son pocos, e incompletos. Una primera tarea en España sería mejorar los sistemas de datos sobre el doctorado ${ }^{3}$. Para mejorar el sistema de educación postgraduada (máster y doctorado) sería necesario que: (a) los programas de doctorado fuesen estudios regulares similares a los programas de licenciatura/ingeniería, (b) más estudiantes de doctorado tengan beca completa, (c) muchos más terminen la tesis doctoral, (d) los/as doctores nuevos sigan realizando investigacion, (e) los programas de doctorado no sean de formación de personal docente propio, y (f) que se institucionalice un nivel intermedio entre licenciatura y doctorado (internacionalmente se denomina master). Además, convendría equilibrar la presencia de la mujer en algunos campos científicos y tecnológicos. En el futuro habría además que evaluar la calidad de las tesis doctorales que se presentan, y el avance que realizan en el conocimiento. En algunas áreas se debe poner en relación con el registro de patentes nuevas.

Los datos internacionales sugieren que las necesidades de investigadores (doctores) y de investigación (investigación y desarrollo o I+D) en España son considerables. Según los indicadores que se utilizan, España debería multiplicar por dos el número de investigadores, por tres la investigación que realiza, y por cinco algunos indicadores como los recursos de bibliotecas y el

${ }^{3}$ Algunos datos esenciales se pueden ver es www.ine.es, en la sección de estadísticas de sociedad/educación. Las comparaciones por universidades aparecen en DE MIGUEL, CAls y VAQUERA (2000 y 2003). Tambien hay datos en Consejo de Coordinación Universitaria (2002), Plan Nacional de Evaluación de la Calidad de las Universidades: Informe Global 1996-2000 (2002). Los datos europeos se pueden consultar en los anuarios de la UNESCO, en los de la OCDE (Education at a Glance) sobre todo el de 2002 sobre indicadores, y en las estadísticas de Eurostat (2002. Una información al día del presente artículo se puede lograr escribiendo a jesusdemiguel@ub.edu, o en el teléfono 934021406.

${ }^{4}$ Para algunas ideas sobre la Universidad en los próximos años se puede ver DE MIGUEL (2003a) 
registro de patentes. El gasto en I+D en España es menos del $1 \%$ del PIB cuando en la media de la Union Europea es del 1,9\%, siendo 2,7\% en Estados Unidos y 2,9\% en Japon. Un problema añadido es la debilidad de la inversion en recursos de $\mathrm{I}+\mathrm{D}$ de la empresa privada, que en España supone apenas el 0,5\% del PIB mientras que en la Unión Europea es el 1,3\%, y en Estados Unidos o Japón más del $2 \%$. Todos los datos sugieren que las tasas de investigadores (doctores) y de recursos de investigación son bajas en España. Sin embargo - como luego demostramos- eso no es enteramente cierto. Las universidades españolas tienen muchos estudiantes de doctorado, e incluso producen bastantes doctores, más de los que reflejan las estadísticas de investigacion: hay muchos doctores, pocos investigadores, y muy poca investigación. Eso sugiere que los nuevos doctores no suelen ser contratados para realizar investigación, sino como docentes en la Universidad, o en otro tipo de trabajo. Pocos doctores se integran en la empresa privada. La tesis doctoral es a menudo la última investigación en una carrera docente. El problema pues no es tener más estudiantes de doctorado, sino que terminen el programa de doctorado (obteniendo el título de doctor); y sobre todo que los/as nuevos doctores sigan investigando. Es un desperdicio de capital humano, ya que son personas que han demostrado la capacidad para realizar investigación. Habría que realizar una política especial para lograr este segundo objetivo, algo así como programas efectivos de becas postdoctorales para investigar.

\section{EL RETRASO EUROPEO}

Actualmente hay un entusiasmo europeísta, que se inicia con la reunión de Bolonia en junio de 1999, pasa por Praga en mayo de 2001, y que se mantiene en la reunión de Berlín en septiembre de 2003 preparando la reunión de Bergen en mayo 2005. La Europa de los Veinticinco, y el Proceso de Bolonia que incluye cuarenta países, propone una convergencia de sus múltiples sistemas universitarios - todos diferentes-hacia un modelo que es una copia aproximada del sistema estadounidense (sin mencionarlo nunca). Una buena parte de la elite universitaria europea ha sido educada en Estados Unidos, por lo que no debe extrañar esa influencia. El entusiasmo europeísta se observa en las medidas de convergencia que propone cambios cosméticos: un sistema de dos ciclos (báchelor y máster/doctorado), la apostilla en inglés a los títulos académicos, y la organización de la enseñanza en créditos europeos (ECTS), con sesenta créditos europeos cada curso académico. Pero esta convergencia meramente formal es una cortina de humo para esconder el verdadero problema de la Universidad europea: su decadencia en el contexto mundial. Hasta hace unas décadas los países del mundo (incluyendo Estados Unidos) copiaban el modelo de la Universidad británica y alemana. Actualmente es al revés. En ese tira y afloja, España no se decide sobre si copiar a Centroeuropa o a Estados Unidos.

La decadencia de la Universidad europea - y en concreto de la españolano se va a arreglar con meros cambios cosméticos, formales o de organización. 
Se observan diez problemas: (a) Europa se ha estancado en un modelo de universidad que apenas forma a la mitad de la juventud, mientras que otros países avanzados del mundo (Estados Unidos, Canadá, Australia) ofrecen educación postsecundaria a más del $85 \%$ de la población. En Europa se mantiene un modelo elitista, que excluye a las clases bajas la oportunidad de la educación postsecundaria. La consecuencia es que la población activa está poco preparada a nivel postsecundario. (b) Europa posee mucho personal de investigación, pero éste investiga poco y su productividad es baja, avanzando el conocimiento menos de lo esperable. Eso se traduce en una tasa de patentes baja (la mitad que Estados Unidos). No sólo la docencia, sino también la investigación y el avance tecnológico están en decadencia. (c) Europa ya no atrae tanto a estudiantes extranjeros, cada vez menos de África, Asia y Latinoamérica. En Estados Unidos, un tercio de la producción de doctores está formado por extranjeros, y en algunos campos (como ingeniería) alcanza el 50\%. (d) Parte del problema es la escasez de recursos; España tiene un presupuesto de educación terciaria que es la mitad que la media de la OCDE. Las carencias de recursos de todo tipo (por ejemplo de bibliotecas) son enormes, y cada vez las diferencias con los países más desarrollados del mundo son mayores. (e) En España, las becas para estudiantes universitarios son muy reducidas tanto en proporción de estudiantes como en cuantía. Prácticamente no existe un sistema de préstamos. La población estudiantil es dependiente de sus padres, lo que crea problemas en la estructura social (entre otros una natalidad bajísima). (f) $\mathrm{La}$ tasa de abandono de la carrera, la de suspensos, y el alargamiento de la duración de la carrera son altas, produciendo que en algunos centros sólo la mitad de estudiantes matriculados terminen la carrera. Seguramente la tasa de fracasos correlaciona además con la clase social más baja de los/as estudiantes que abandonan, contribuyendo a un modelo más elitista que el de acceso ${ }^{6}$. (g) En España, la situación del doctorado es peor aún, pues termina uno de cada cinco estudiantes que empiezan un programa de doctorado. Además, los/as que obtienen el título de doctor luego apenas investigan. En consecuencia la situación es de abundancia de estudiantes, cierta plétora de doctores, pero una insuficiencia manifiesta de investigación. Las personas realizan un doctorado para conseguir un puesto de trabajo (docente), no para investigar. (h) Falta una estratificación de universidades que suponga una especialización de funciones, así como una dedicación diferente a la formación de docentes e investigadores. (i) Durante décadas la selección del profesorado ha sido endogámi$\mathrm{ca}$, atendiendo a valores de amistad, lealtad, e incluso de lengua o tendencia ideológicas. Superar la estructura actual del personal docente va a requerir varias décadas más, si es que la legislación actual logra superar el problema

${ }^{5}$ Es un problema más complicado, no se trata sólo de atraer estudiantes, sino de que puedan salir de sus países respectivos. Los últimos datos se pueden ver en «Characteristics of recipients of earned doctorates 2002» en The Chronicle of Higher Education (12 diciembre 2003), p. A10.

6 «La clase alta tiene cinco veces más posibilidades de ir a la Universidad» El País, sección de «Cataluña» (9 mayo 2003), pp. 1 y 9 . Incluye datos de la Encuesta Metropolitana. 
endogámico. Algunas universidades locales están empeñadas en burlar la legislación, controlando el acceso de nuevos profesores y reforzando las barreras lingüísticas de algunas comunidades. (j) Otra carencia a nivel comparativo con el mundo es la falta de personal no docente (lo que se llama PAS), que todavía concentra poco interés en las políticas universitarias. (k) En España se producen progresos, como la extensión del número de estudiantes (cuya tasa actual está estancada) o el avance de la tasa de feminización del alumnado (que alcanza ya a 120 mujeres por cada cien varones). Pero la feminización no ha llegado en algunas áreas (como ingeniería), ni tampoco al profesorado (que cuenta sólo con el $34 \%$ de mujeres). En los estratos de catedráticos, cargos, y poder universitario la dominación masculina es rampante ${ }^{7}$.

La euforia europeísta parece ser contagiosa. La realidad es que no hay estudios sociológicos sobre los diez problemas que acabamos de enumerar. Más bien se observa un cierto tabú en la investigación de la Universidad o en la investigación de la investigación. En cualquier caso, la situación española debe analizarse en el marco de referencia de Europa. En innovación tecnológica la Unión Europea mantiene un nivel de retraso cada vez más evidente respecto de Estados Unidos (y Japón). Las patentes de alta tecnología en Estados Unidos son casi el doble que en Europa. Una preocupación europea actual es desarrollar más la investigación, la tasa de investigadores, su productividad, y especialmente la producción de patentes. En comparación con la educación terciaria en Estados Unidos, la Universidad europea es cada vez menos competitiva, atrae menos estudiantes extranjeros, sigue sufriendo tasas altas de brain drain o «fuga de cerebros», y padece una competencia creciente de educación transnacional a menudo en inglés. A pesar del proceso iniciado por la Declaración de Bolonia en 1999, no puede hablarse de "un modelo único» de Universidad europea, ni siquiera de un proceso claro de integración o convergencia, dado que las diferencias internas son considerables. El sistema universitario europeo continúa siendo caótico. En un contexto global las universidades europeas están perdiendo prestigio. La dominación estadounidense de la tecnología avanzada, así como de las asociaciones profesionales científicas, es evidente. Con casi seiscientos mil estudiantes extranjeros, las universidades de Estados Unidos no sólo forman a las elites docentes e investigadores de su país, sino además a las del mundo entero. Al menos un $30 \%$ de los doctores que se producen en Estados Unidos son extranjeros; en algunos campos como ingeniería suponen el $60 \%$ según los datos publicados en The Chronicle of Higher Education. A pesar de los esfuerzos integradores, de movilidad, y de calidad/acreditación, Europa no parece estar consiguiendo mejorar sus universidades, ni la producción de investigadores (doctores). El esfuerzo actual se centra en homologar los estudios mediante la homogeneización del sistema de créditos implementando el ECTS (European credit tranfer system). Se supone que debe haber una integración de ciclos de estudios (hacia un sistema binario), y de títulos (hacia un sistema de bachelor/master/doctor

7 Sobre la situación española en un contexto europeo (y mundial) pueden verse los datos en De Miguel y Sarabia (2003) y Sarabia y de Miguel (2004). 
con una estructura de $3 / 2 / 3$ años) antes del año 2010 , pero la velocidad de cambio es lenta. España está especialmente atrasada en este proceso de convergencia ${ }^{8}$.

Una explicación del retraso europeo es que la proporción de población activa con educación superior es casi el doble en Estados Unidos que en Europa. La proporción de población con estudios post-secundarios (lo que en España normalmente se denomina educación «superior» o «universitaria», aunque son conceptos diferentes) en Estados Unidos es mucho mayor que en Europa. En Norteamérica se ha conseguido que más del $85 \%$ de los/as jóvenes realicen estudios postsecundarios, mientras que en Europa esa proporción se ha quedado estancada en torno al $50 \%$. Una población más educada tiende a ser más productiva. La cantera de donde escoger doctores es también mayor. Las posibilidades de inversiones y productividad en $\mathrm{I}+\mathrm{D}$ es más elevada. En Estados Unidos, Australia o Canadá se ha conseguido la casi universalización de la educación terciaria (superior o universitaria), mientras que Europa sigue manteniendo un modelo elitista que a ese nivel sólo educa a la mitad de los jóvenes. La mitad que no va nunca a la Universidad es la clase baja, inmigrantes, y poblaciones remotas. Pero las personas ausentes de la Universidad ya no son mujeres, hasta el punto de que en Europa hay aproximadamente 120 mujeres en la Universidad por cada cien varones. Es curioso que en Europa, donde se considera que la Universidad es una responsabilidad pública y en donde los precios de matrícula son bajos, hay pocos estudiantes universitarios, y en cambio en otros sistemas universitarios más privatizados $\longrightarrow$ donde se demanda un esfuerzo económico familiar o personal mayor - la tasa de escolarización universitaria es alta. Algunos críticos sugieren que donde la

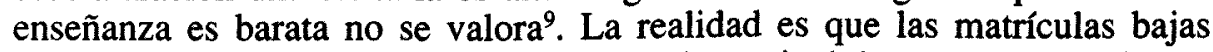
suponen ingresos bajos para la Universidad, un nivel de recursos reducido, y por lo tanto niveles de calidad universitaria escasos. Otra explicacion es que Europa mantiene tasas de desempleo altas en personas con estudios universitarios. Las razones son múltiples, pero en ocasiones contradictorias. La realidad es que el prestigio de la Universidad europea está descendiendo, tal y como reconocen las sucesivas reuniones para reformar el sistema universitario europeo en 1999 (Bolonia), 2001 (Praga), 2003 (Berlín) y Bergen en mayo de 2005 .

En el contexto europeo, según los datos de la OCDE, España es el segundo país (después de Finlandia) con la proporción mayor de jóvenes matriculados en la Universidad, pero la razón es que muchos suspenden asignaturas, repiten curso, y otros abandonan la carrera. El número de años necesarios para terminar la carrera es excesivo. La productividad de las carreras es baja y la

${ }^{8}$ Al final del gobierno conservador (del PP), el Ministerio de Educación, Cultura y Deporte acelera este proceso de convergencia con el documento: La integracion del sistema universitario español en el Espacio Europea de Enseñanza Superior: Documento-marco (2003). Véase dos artículos sobre este tema de Jesús M. DE MiGUel (2003b y 2004a).

9 Víctor Pérez Díaz y Juan C. Rodríguez (2001): Ver la recensión en Revista Española de Investigaciones Sociológicas 96 (2001), pp. 311-325. También en Jesús M. DE MiguEL (2002b). De Víctor Pérez Diaz ver además: Pérez Dfaz 2003 y 2004. 
del doctorado más baja aún, y cada vez lo es más. El éxito no es que las/os jóvenes - son cada vez más mujeres- se matriculen en la Universidad o en el doctorado, sino que realmente terminen (y aprueben) la tesis doctoral. La falta de productividad es el problema principal del sistema universitario español. Son los países nórdicos europeos (Finlandia, Suecia, Dinamarca, incluso Holanda) los que presentan una situación mejor dentro de Europa. Los países meridionales -España entre ellos- siguen siendo el rabo por desollar de Europa. Pero no se puede hablar de la Universidad de Europa como un todo. Dentro de los países europeos las diferencias son considerables, y los modelos de organización divergentes. Pero tanto en I+D como en Universidad los (escasos) recursos existentes suelen estar bastante centralizados.

En este contexto europeo precario que sugieren los datos macro, España ocupa una de las posiciones más bajas. Junto con Portugal y Grecia, España está situada en los últimos puestos en I+D y en calidad de universidades. La distancia con el resto de Europa es grande y creciente. La producción de doctores, investigadores, y recursos en I+D (como porcentaje del PIB) son indicadores que demuestran la posición retrasada y problemática de España. Apenas hay políticas dirigidas al tercer ciclo (doctorado, master y postgrado) en España, y las escasas medidas que hay son poco efectivas. Las causas del retraso español son varias. Primero, la inversión en I+D es muy baja y está mal distribuida. Eso se añade a un presupuesto en educación escaso, en donde la educación superior tiene proporcionalmente menos recursos aún. El presupuesto del sistema universitario público debería de recibir -como se sabe por los datos globales - el doble o incluso el triple de inversiones. La inversión de las empresas privadas en $I+D$ es escasa. Las tasas de empleo en alta tecnología son bajas. El número de patentes que se registran es escaso. La productividad de los estudios universitarios - sobre todo los de doctorado- es débil. Los recursos de biblioteca y de internet son reducidos. Sólo una universidad española (la Complutense de Madrid) supera los dos millones de libros en su biblioteca, que suele considerarse el nivel mínimo para ser considerada como universidad-investigadora. La Universidad española apenas atrae extranjeros $(1,5 \%$ de extranjeros en las carreras de primero o segundo ciclo). En el contexto de la sociedad global los recursos de ordenadores y de conexión a internet son más bajos de lo esperable, aunque los de telefonía móvil son altos. Relacionado con todo esto, las tasas de desempleo europeos son elevadas; las de España son de las más altas. El paro en mujeres es el doble que el de varones, y en jóvenes es extraordinariamente alto. En investigación España se sitúa en una posición muy baja en Europa, teniendo en cuenta que la situación comparativa de la Unión Europea con Estados Unidos es ya preocupante.

Se ofrecen explicaciones de todo tipo ${ }^{10}$. Se culpabiliza a la Universidad española acusándola de ser tradicional, elitista, endogámica y poco productiva. La proporción de personas que nunca acaban la carrera es alta, alcanzando

10 Se puede ver en De Mrauel (2002a). 
en bastantes carreras la mitad de estudiantes. La proporción de no presentados, suspensos, y abandonos es también elevada ${ }^{11}$. La media de años que se necesitan para terminar la carrera es excesiva, en algunos centros el doble de lo establecido. El modelo integrado europeo con el que se sueña —el Proceso de Bolonia - pretende reducir esos años, diseñando licenciaturas universitarias de tres años reales, para que los/as jovenes se integren pronto en el mercado de trabajo. El modelo es 3-2-3, es decir tres años para bachelor, luego dos para máster, y tres años más para doctor. Eso va a suponer un ajuste difícil para el sistema universitario español -como se señala en algunos documentos oficiales europeos - pues las carreras son de cuatro o cinco años (incluso de seis en algunos casos). En el doctorado esos problemas se multiplican: muchas personas empiezan pero pocas terminan; los datos indican que cada vez la proporción de los que terminan es menor. La productividad está en torno al $20 \%$ en seis años, es decir sólo un/a estudiante de doctorado de cada cinco termina el doctorado en un plazo de tiempo razonable. La proporción de becas de doctorado es muy baja, insuficiente para que estudiantes maduros puedan realmente dedicarse al doctorado. No hay estudios que evalúen esos fracasos, ni parece que sea un tema que atraiga el interés de los/as investigadores. A pesar del fracaso relativo de los programas de doctorado, las universidades españolas no están reformando sus sistemas de doctorado de forma efectiva.

La explicación de que la investigación en España está retrasada porque no hay suficientes programas de doctorado, o porque no se producen bastantes doctores, es falsa. No hay universidades que produzcan muchos doctores, pero todas las universidades titulan doctores. El problema es que en realidad no son programas de formación de personal investigador, sino más bien de formación de personal docente propio. Apenas hay movilidad de nuevos doctores, y el sistema es endogámico. Tienden a terminar el doctorado las personas que ya son profesores de la misma universidad. No se trata de un programa real de doctorado (es decir, de formación de investigadores) sino un sistema de cooptación de profesores ${ }^{12}$. De cada diez estudiantes de doctorado uno o dos son extranjeros (15\%), la mayoría latinoamericanos. Es una proporción que es la mitad que en Estados Unidos, pero que en la historia española es relativamente alta. Los estudiantes y doctores extranjeros siguen pautas diferentes a los nativos, y apenas son asimilados por las universidades locales. Son muchos si se compara con el $1,1 \%$ de estudiantes extranjeros en las carreras, o el $0,9 \%$ entre estudiantes que terminan la carrera.

Por vez primera en la historia de España la mujer accede al doctorado y al título de doctor prácticamente en igualdad de condiciones que el varón (Vaquera y De Miguel, 2001). Eso es gracias a que entre las personas que terminan la carrera la proporción de mujeres supone ya el 58\%. Elizabeth

${ }^{11}$ Eso también preocupa en Estados Unidos como puede comprobarse en el artículo de Scott SMALLWOOd (2003).

${ }_{12}$ La Ley de Universidades de Cataluña (LUC, febrero 2003) trata de evitar eso con el requisito de que el doctorado provenga de otra universidad. Véase el comentario en DE MIGUEL. (en prensa). 
Vaquera ha estudiado esta problemática. El doctorado no discrimina especialmente a grupos minoritarios, sino que se discrimina en bloque, al no formar un mercado competitivo inter-universitario, ni acceder a la empresa privada para realizar investigación tecnológica avanzada. En nuestra opinión, el doctorado, la enseñanza virtual, y la integración en Europa son las tres reformas pendientes del sistema universitario español.

\section{COMPARACIÓN CON ESTADOS UNIDOS}

A principios del siglo xx Estados Unidos copiaba el modelo universitario británico y alemán; un siglo después es al revés. De las cuatro mil instituciones de enseñanza postsecundaria estadounidenses, apenas un centenar son universidades-investigadoras. Pero éstas forman al profesorado, y sobre todo al personal investigador más avanzado de todo el mundo. Sus programas de doctorado son el punto de referencia mundial. Se publica el informe anual del National Opinion Research Center (NORC) de la Universidad de Chicago titulado Doctorate Recipients From United States Universities: Summary Report 2001. Algunas tablas y datos son accesibles en The Chronicle of Higher Education ${ }^{13}$. Estados Unidos produce 40.744 doctores al año, lo que supone aproximadamente 2,7 doctores por cada mil estudiantes en educación post-secundaria. Pero al año siguiente (2002) se reduce a 39.955 nuevos doctores. No hay estadísticas internacionales fiables sobre lo que es «mucho» o «poco» en la producción de doctores. Intuitivamente se considera que Estados Unidos produce muchos doctores. Pero entre los nuevos doctores el $29 \%$ son extranjeros sin visado permanente. Las universidades-investigadoras de Estados Unidos forman al profesorado (e investigadores) más destacado del mundo. Sin embargo, la preocupación actual es que el número de doctores está bajando ${ }^{14}$. En Estados Unidos aumenta el número de estudiantes terciarios - son ya 15 millones, prácticamente diez veces más que en Españapero desciende el número de doctores nuevos. En el trienio 1998-2001 la producción de doctores nuevos ha descendido un $4 \%$. Esta tendencia preocupa en Norteamérica.

A nivel comparativo España tiene un tercio más de doctores nuevos cada año que Estados Unidos. Los casi seis mil doctores que se producen anualmente (5.984 obtienen el título de doctor en 1999) suponen una tasa de 3,6 doctores por cada mil estudiantes terciarios, es decir una tasa $33 \%$ más alta que Estados Unidos. Pero como un tercio de los doctores que obtienen el título de doctor en Estados Unidos son extranjeros, su tasa real de doctores es alrededor de la mitad que en España. Eso debe hacer reflexionar a las perso-

13 «Number of U.S. doctorates awarded falls, but women gain in share total» The Chronicle of Higher Education (22 noviembre 2002), pp. A13-A14. También se puede consultar www.norc.uchicago.edu/issues/docdata.htm. El proceso de feminización de la Universidad española se analiza en el artículo VAQUERA y DE MIGUEL (2001).

${ }^{14}$ La quinta parte (20\%) son de Ciencias de la Salud, muchos de ellos/as de Medicina. 
nas que creen que España produce pocos doctores. Se podría argumentar que entre los doctores extranjeros que se forman en las universidades estadounidenses hay españoles, que luego vuelven a España. Pero España tiene la tasa menor de Europa de estudiantes en el extranjero (también la tasa menor de estudiantes extranjeros estudiando la carrera en España). Los datos comparativos sugieren que si Estados Unidos está preocupado porque su número de doctores desciende, la situación en España es la inversa.

La explicación que se ofrece en Estados Unidos es que el descenso en estudiantes de doctorado, y sobre todo en doctores nuevos, se debe a la inseguridad y falta de empleo académico para profesores que dominó en los años noventa del siglo pasado. El panorama desalentador produjo que pocas personas decidiesen realizar el doctorado. Durante unos años hubo en Estados Unidos un exceso de doctores en el mercado de trabajo, y una saturación de plazas. Esto produjo una falta de puestos de profesores, y especialmente de carreras académicas permanentes (lo que se denomina tenure track). Es posible que ante la falta de puestos de trabajo seguros las personas decidiesen no iniciar estudios en programas de doctorado. Pero el declive actual no está tanto en Humanidades, que es donde hubo más saturación, sino en Ingeniería. Por lo tanto, la explicación de la falta previa de salidas profesionales no es plausible. La realidad actual es que cada vez hay menos doctores en ciencias y en ingenierías en Estados Unidos ${ }^{15}$. El descenso es del $6 \%$, y bastante homogéneo en todas las ingenierías, configurando una pauta sistemática. El resto de campos (conjuntos de áreas) de conocimiento desciende también pero solamente un $1 \%$. Quizás la explicación indirecta es la creciente incorporación de la mujer al doctorado, prefiriendo carreras que no son de ciencias experimentales ni de ingeniería. Pero la proporción de extranjeros entre los doctores nuevos aumenta, y los extranjeros son mayoría en carreras de ingeniería y ciencias. Las explicaciones que se ofrecen no son pues concluyentes.

En la mayoría de los países avanzados hay cada vez más mujeres entre los estudiantes de doctorado, e incluso entre los doctores nuevos. En este último grupo - personas que este año obtienen el doctorado- las mujeres son el $44 \%$. En el año 2002 las mujeres son ya el $45,4 \%$. Pero como entre los estudiantes graduados extranjeros abundan los varones, si se contabilizan únicamente los ciudadanos/as de Estados Unidos, la proporción de mujeres representa el $49,5 \%$. No todos los campos son igualmente favorables a la mujer: en ingeniería hay sólo un $17 \%$ de mujeres doctoras, en ciencias $25 \%$, y en empresa $34 \%$. Entre los doctores de ciencias sociales la mujer es ya mayoría (54\%), y más aún en educación (65\%). En comparación, el proceso de feminización es más avanzado en España que en Estados Unidos, pues entre los estudiantes de doctorado las mujeres son ya el $53 \%$

Cada vez hay más extranjeros en los programas de doctorado estadounidenses, suponiendo un incremento del $3 \%$ de doctores. Del total de doctores el $66 \%$ son ciudadanos/as de Estados Unidos, y son extranjeros con visado

${ }^{15}$ Como en España, en ese estudio incluimos la carrera de arquitectura dentro de ingeniería. 
temporal el $24 \%$. Con visado permanente hay un 5\% adicional, pero del $6 \%$ del total no se tiene información. Se puede estimar que alrededor de un tercio de los doctores nuevos en Estados Unidos son extranjeros. El 24\% de extranjeros-sin-visado se eleva al $26 \%$ en el caso de los doctorados en empresa (business), 38\% en ciencias, y 50\% en ingeniería (57\% en el año 2002). Mujeres y extranjeros-a pesar de su carácter de minorías- son grupos que aumentan relativamente su proporción, aunque la media general de doctores nuevos desciende un poco.

Pero no todas las minorías pueden presentar un éxito igual. En Estados Unidos los negros/as sólo representan un 6\% del total de doctores nuevos, y los hispanos/as un porcentaje incluso menor (4\%). Sin embargo, es el doble entre asiáticos (8\%). Los negros están pues sub-representados, especialmente en ciencias (únicamente hay un $2,7 \%$ de negros) y en ingeniería $(3,8 \%)$. Además la tendencia es a disminuir la proporción de negros que obtienen el doctorado; también cada vez hay menos hispanos, e incluso menos americanos nativos (indios). De las minorías étnicas sólo aumentan los asiáticos, con un incremento anual del $2 \%$, siendo ya el $17 \%$ en ingeniería. Curiosamente los/as blancos están sobre-representados en Humanidades (82\% subiendo a $85 \%$ en el año 2002) que es donde hay más problemas de salidas profesionales ${ }^{16}$.

En el mundo se reconoce que los/as doctores pueden tener una carrera exitosa fuera de la Universidad. Esa tendencia creciente representa un cambio interesante. Según la encuesta de NORC a doctores nuevos, en Estados Unidos sólo un 35\% está buscando trabajo como profesor universitario. Este grupo es mucho menor entre ingenieros $(12 \%)$, ciencias $(15 \%)$ o en ciencias de la salud (16\%). Un tercio - 30\% - tiene planes de trabajo postdoctoral: $19 \%$ en la empresa privada, $4 \%$ en el Gobierno, y $3 \%$ en alguna ONG. El trabajo postdoctoral en la empresa privada asciende al $51 \%$ entre ingenieros. Los/as doctores que más desean un trabajo en la Administración Pública son los de ciencias sociales $(7 \%)$. Los más entusiastas para trabajar en ONG son los/as doctores de campos profesionales (10\%). Una cuarta parte del total de doctores nuevos desea seguir estudiando o realizando investigación. Estas estadísticas indican que el doctorado prepara cada vez menos para ser profesor de universidad, más para un trabajo real en el sector público o privado (o sin ánimo de lucro como las ONG), o para seguir investigando. El doctorado se convierte en el nivel más alto posible de formación académica, y no en un sistema reproductor de la Universidad. Es posible que la misma tendencia se produzca en Europa, y así también en España.

En el año 2002 desciende aún más el número de nuevos doctores en Estados Unidos bajando de cuarenta mil (39.955) con una edad media de 33,3 años, habiendo transcurrido de media 7,5 años en graduate school. La proporción de mujeres es $45,4 \%$, y entre los nuevos doctores los que son ciudadanos de Estados Unidos descienden al $65 \%$. Del total aproximadamente un $27 \%$ deciden seguir estudiando. Entre nuevos doctores solamente un $36 \%$ busca empleo

${ }^{16}$ Los datos más recientes, para el año 2002, se pueden ver en The Chronicle of Higher Education (12 diciembre 2003), p. A10. 
docente en la Universidad. Pero hay que tener en cuenta que uno de cada diez nuevos doctores no tienen todavía planes fijos tras el doctorado ${ }^{17}$. El análisis de estos datos sobre Estados Unidos suponen ciertos problemas en relación con el doctorado. De forma resumida serían estos cuatro problemas:

a) Escasez de doctores, pero se reconoce que la inversión en el doctorado es cara y a largo plazo. De media, los estudiantes están matriculados en un programa graduado (de doctorado) siete años y medio. En el caso de Humanidades este periodo se eleva a nueve años. Desde el BA - título equivalente a licenciado- al título de doctor transcurren diez años; en Educación o Pedagogía son 19 años. La edad media a la que se obtiene el título de doctor en Estados Unidos es actualmente 33 años. En campos profesionales (Medicina, Derecho) es 39 años, y en Educación 44 años. Lo peculiar del sistema estadounidense es que casi la mitad de los doctores nuevos provienen de otra carrera diferente (en el $47 \%$ de los casos); en empresa (business), por ejemplo, el $66 \%$ de los doctores provienen de otra carrera. Eso es algo que ocurre pocas veces en España, y que seguramente va a ser el cambio más sustancial en el futuro. La carrera de doctorado es larga - y cara - pues supone una década entera de la vida de una persona (10,2 años tras el bachelor), aunque la duración media tiende a disminuir un poco. Existe un cierto acuerdo de que debería acortarse aún más.

b) Faltan doctores nacionales, dado que hay ya una escasez de doctores, y lo que más crece es el número de extranjeros. Una tasa de 2,7 doctores por cada mil estudiantes de licenciatura/ingeniería no es elevada. Sobre todo, teniendo en cuenta que entre una quinta parte y un tercio son extranjeros, la mayoría de los cuales se vuelven a su país. En doctorados en ingeniería sólo un $39 \%$ son ciudadanos estadounidenses. Estados Unidos educa a la elite universitaria docente e investigadora del mundo, pero es a costa de tener problemas de reposición de su propio profesorado. Se soluciona con el brain gain, en forma de profesionales ya formados que importa de otros países del mundo.

c) Es necesario que el proceso de feminización continúe y se complete. Entre los doctores nuevos hay un $44 \%$ de mujeres, pero dado que hay más mujeres estudiando en la Universidad, ese porcentaje debería elevarse por lo menos hasta el $50 \%$. El esfuerzo tiene que ser mucho mayor en ingeniería donde las mujeres son únicamente el $17 \%$, o en ciencias $25 \%$. Incluso en business la proporción de doctores nuevos que son mujeres es sólo $34 \%$ (sube a $38 \%$ en el año 2002). Hay pues todavía un cierto camino por recorrer, que supone no tanto un incremento general de doctores, como una mejor distribución por campos

${ }^{17}$ Los datos aparecen en una tabla en el mismo número de The Chronicle of Higher Education. 
específicos. La separación por género entre doctorados «de ciencias» y «de letras» debería desaparecer.

d) Se precisan salarios mejores, y condiciones de trabajo más ventajosas, para el profesorado universitario. Si se quiere atraer más estudiantes a realizar el doctorado (y terminarlo) es preciso mejorar las condiciones actuales de salario, poder, seguridad, y libertad en el empleo. En Estados Unidos el salario medio del profesorado universitario aumenta a más velocidad que el coste de la vida. Pero se produce una cierta dicotomización (o segmentación) de empleo, con un incremento de la proporción de profesorado temporal. En realidad no es una característica únicamente norteamericana: la proporción de contratos temporales en la Universidad aumenta en casi todos los países. A menudo son también contratos a tiempo parcial. Ambos tipos ofrecen una seguridad de empleo baja. Quizás esa característica equilibra que los salarios generales aumentan más de lo esperable. El poder del profesorado está disminuyendo, pues las universidades son cada vez instituciones más complejas (y caras) que requieren una gestión empresarial y profesional. Muchos cargos o tareas que antes era desempeñadas por catedráticos son cubiertas crecientemente por administradores y gerentes. En cuanto a la libertad académica no se observan tendencias claras. Hay diferencias según la dependencia de la universidad, pues en las privadas la libertad académica que tienen los/as profesores es menor; eso es más evidente a la hora de definir planes de estudios, programas, y contratación de otros/as profesores.

Estos cuatro problemas que se refieren al caso de Estados Unidos pueden ser identificados en el caso español, aunque con matizaciones. Veamos pues en qué sentido la experiencia de otros países se puede incorporar a la situación española, para poder planificar el futuro (De Miguel, 2003a).

\section{ESPAÑA: MUCHOS ESTUDIANTES, POCOS DOCTORES}

Existe un cierto mito sobre la falta de doctores en España, o su mala preparación. Con los datos disponibles es imposible medir la calidad de los doctores nuevos. Pero la cantidad de doctores nuevos no puede considerarse escasa: 5.984 nuevos doctores en el año 2000. En números absolutos eso supone 6,8 veces menos doctores que en Estados Unidos; pero ese número es prácticamente igual a la diferencia de población: en el mismo año España tiene siete veces menos población que Estados Unidos (39,5 millones respecto a 278,1 millones). En el total las tasas coinciden. Sin embargo, Estados Unidos tiene 15 millones de estudiantes terciarios, aproximadamente entre ocho y diez veces más que España ${ }^{18}$. Para comparar las tasas lo importante no es tanto la

${ }^{18}$ Los datos de Eurostat (2002) para el año 1999 son 13.769 .000 estudiantes terciarios en Estados Unidos y 1.787 .000 en España. Pero estos datos subestiman las cifras de Estados Uni- 
población total como el número de estudiantes terciarios. La diferencia en el cálculo supone que España tiene -proporcionalmente- un $47 \%$ más doctores nuevos cada año que Estados Unidos. Además como en Norteamérica aproximadamente un tercio de los doctores nuevos son extranjeros, la producción de doctores en España es relativamente mayor ${ }^{19}$. Pero si se evidencia que los recursos de investigación españoles (en proporción del PIB) son la tercera parte que en Estados Unidos, hay que suponer que o los doctores que se producen recientemente en España no son suficientes para superar las carencias de décadas anteriores, o bien que muchos doctores españoles no investigan.

El sistema universitario español actual es estable, apenas crece ya, debido a que hace dos décadas la natalidad descendió súbitamente. Cada vez hay menos población joven, pero aumenta todavía el deseo de estudiar en la Universidad, con lo que las tasas se equilibran. La población universitaria está estable en torno a 1,6 millones de estudiantes, creciendo muy poco, e incluso descendiendo ligeramente algún año. Entre 1996 y el año 2000 la Universidad española crece un $8 \%$, lo mismo ocurre con la producción de doctores nuevos. El doctorado es un sector que se regula pero no en la entrada (estudiantes que inician los estudios de doctorado) sino en la salida. La producción real de doctores es bastante estable. Cada vez hay más estudiantes de doctorado, pero siempre termina el mismo número, lo que indica que la productividad no hace más que descender. Dado que las necesidades de profesorado apenas aumentan proporcionalmente (pues el número de puestos docentes está ya saturado y el número de estudiantes no se incrementa) la bolsa de doctores no contratados por el sistema universitario es cada vez mayor.

Los datos proporcionan una visión global de la situación. En España hay actualmente 1,6 millones de estudiantes universitarios, y acaban la carrera unos 215.000 estudiantes al año. Un $44 \%$ de esos estudiantes terminan una carrera corta (diplomatura o ingeniería técnica) que no les permite empezar el doctorado al año siguiente. La población estudiantil anual que puede empezar estudios de doctorado es aproximadamente 120.000 estudiantes. Al año siguiente hay matriculados en doctorado unos 64.000 estudiantes. Pero la matrícula tiene que dividirse entre los dos años obligatorios de formación doctoral, lo que supone unos 32.000 estudiantes de doctorado. Estos datos, si son fiables, sugieren que al menos uno de cada cuatro estudiantes $(27 \%)$ que se licencian siguen estudios de doctorado, lo que intuitivamente parece una

dos y exageran las españolas. En total, la Unión Europea /de los Quince) tiene 12,5 millones de estudiantes terciarios, o sea el $91 \%$ de la cantidad que tiene Estados Unidos. Pero hay que tener en cuenta que la Europa de los Quince tiene un $36 \%$ más población que Estados Unidos: 378 millones de habitantes en Europa versus 278 en Estados Unidos. Europa debe realizar un esfuerzo para que más jovenes se matriculen en la Universidad; el ideal sería tener seis millones más aproximadamente, lo que supone alrededor del $50 \%$ más de los que actualmente tiene. El esfuerzo a realizar es pues considerable.

19 En el año 2002, en Estados Unidos, sólo el 65\% de los nuevos doctores son ciudadanos de ese país, pero las estadísticas incluyen un $7 \%$ de no se sabe. Con visado temporal son el $24 \%$ y con visado permanente el $4 \%$. En ingenierías el visado temporal supone el $52 \%$ de los doctores nuevos, en ciencias son el $38 \%$ y en business el $31 \%$. 
cantidad excesiva. Hay que tener en cuenta que en el doctorado hay un $15 \%$ de estudiantes extranjeros, la mayoría de los cuales no han realizado la carrera previa en España. Los datos son oficiales del Ministerio. Pero en el mismo año, la cantidad de nuevos doctores que producen todas las universidades españolas son unos 6.000 . Si se pone en relación este número con los/as estudiantes que empezaron el doctorado seis años antes (que son unos 27.000) terminan el doctorado uno de cada cinco estudiantes (22\%). La productividad es pues bajísima. En el año 2000 se logra que en España no haya discriminación por género, pues entre estudiantes de doctorado el $50 \%$ son mujeres, y su participación sigue creciendo. Los datos provisionales del año 2002 suponen un $53 \%$ de mujeres entre estudiantes de doctorado. Sin embargo, la proporción de títulos de doctor que se conceden a mujeres es algo menor: $44 \%$. La proporción de estudiantes extranjeros entre los estudiantes de doctorado es del $15 \%$, de los cuales las dos terceras partes son de las Américas ${ }^{20}$.

El incremento de producción de doctores no es excesivo: $25 \%$ en una década. Eran 4.776 en el año 1990, y aumentan a trompicones (unos años sube un poco el número, otros disminuye ligeramente) hasta 5.984 en 1999. Teniendo en cuenta que en esa misma década el número total de estudiantes universitarios aumenta un $48 \%$ (pasa de 1,1 a 1,6 millones) y el número de estudiantes que terminan una carrera larga - que permite empezar un doctorado- aumenta un $64 \%$ (de 73.000 a 120.000 estudiantes), el crecimiento del doctorado puede considerarse como contenido. Los datos oficiales existentes no permiten conocer exactamente el número de estudiantes que inician el doctorado en España cada año, lo que es una limitación grave a la hora de realizar la presente investigación empírica. Se ofrecen datos del número total de estudiantes de doctorado, se entiende que matriculados en primero o segundo curso de doctorado (pues la matrícula dura dos cursos académicos enteros). Eso permite dividir, salomónicamente, el número por dos, estimando que el abandono entre el primer año y el segundo no es muy elevado, o al menos es constante (desestimando el abandono que se produce tras el primer año de doctorado). Eso supone que en la década de los noventa los estudiantes que empiezan el doctorado crece desde 18.116 hasta 32.146 (un aumento del $77 \%$ ). Es un aumento proporcional igual al crecimiento de estudiantes españoles que terminan la carrera (que pasa de 121.392 en 1990 a 214.527 en 1999). Los estudiantes que terminan una carrera larga son menos, entre el $60 \%$ y el $56 \%$ del total. Eso supone que el número de estudiantes que terminan una carrera larga oscila entre 73.284 en 1990 y 120.157 en $1999^{21}$. Si se compara con los/as estudiantes que realmente empiezan el doctorado al año siguiente (pasan de 18.116 a 32.146) la relación entre los/as estudiantes que terminan la carrera larga y que al año siguiente empiezan el doctorado varía entre el $25 \%$ en 1990 $y$ el $27 \%$ en 1999. En algunos años intermedios (como 1993 y 1994) la proporción sube al $34 \%$. Con estos datos oficiales no puede considerarse el doctorado como un sistema marginal $\longrightarrow$ residual - pues se matriculan al menos

${ }^{20}$ No hay datos completos de extranjeros entre los que obtienen el título de doctor.

${ }^{21}$ Son estimaciones a partir de los datos oficiales. 
una cuarta parte de estudiantes potenciales ${ }^{22}$. El doctorado es una salida usual para uno de cada cuatro licenciados/as (o ingenieros/as). Quizás la popularidad del doctorado dependa de la dificultad de los/as nuevos licenciados por obtener trabajo. Según los datos de la EPA (Encuesta de población activa) se sabe que el mercado laboral español de los años noventa implica una espera de los nuevos licenciados antes de conseguir su primer empleo estable. Quizás por eso algunas personas que terminan la carrera empiezan los estudios de doctorado, pero sin vocación investigadora (incluso sin vocación docente). Sorprende en España la proporción alta de estudiantes que comienzan el doctorado, casi tanto como la proporción baja de los que obtienen el título de doctor.

La Tabla 1 muestra que el sistema de doctorado en España es relativamente importante. Tras medio siglo de enorme desarrollo de la Universidad, en que se duplica la matrícula de estudiantes universitarios, la década de los noventa 1990-2000 supone un incremento moderado de estudiantes universitarios, en torno al $48 \%$. Se pasa de 1,1 millones a 1,6 millones. En los años más recientes se observa que la población estudiantil universitaria crece ya muy poco, incluso algún año desciende ligeramente, compensado solamente por el crecimiento del número de estudiantes de doctorado. La productividad -que tradicionalmente era baja - está aumentando: el incremento de estudiantes que terminan la carrera es $77 \%$. El éxito parece deberse, en parte, al incremento de carreras cortas, diplomaturas, pues la proporción de estudiantes de carreras largas (licenciaturas/ingenierías) desciende lenta pero sistemáticamente del $60 \%$ al $56 \%$ del sistema universitario. Los datos de la tabla suponen que aproximadamente 120.000 estudiantes terminan una carrera larga, que les faculta para seguir adelante hacia un doctorado. Ya se ha comentado que el dato exacto de estudiantes que realmente empieza un doctorado no es posible de obtener con las estadísticas oficiales españolas. Hay que estimarlo del conjunto del total de estudiantes matriculados en doctorado (a veces se menciona como «tercer ciclo»). Se estima que son unos 30.000. El número de estudiantes que empiezan el doctorado experimenta un crecimiento del $77 \%$ en la década de los noventa, que es igual al incremento de estudiantes que termina la carrera. Así se puede estimar la proporción de estudiantes que terminan una carrera larga y que al año siguiente empiezan un doctorado. Ese porcentaje es alrededor de la cuarta parte (27\% en 1999) pero en algunos años ha llegado a ser la tercera parte. Lógicamente no son las mismas personas, pues a menudo hay una espera de varios años antes de empezar el doctorado, y también hay los/as que vienen del extranjero. Al no haber una correlación por nombres, los datos son solamente aproximativos, pero suponen un buen indicador de la popularidad del doctorado en España.

Los datos recientes del Ministerio de Educación, Cultura y Deporte (curso académico 2000-2001) señalan que un tercio de estudiantes de doctorado tienen más de treinta años: $21 \%$ entre 31 y 40 años, y $11 \%$ tienen más de cuarenta años. En el 2002 esta proporción conjunta sube al 36\%. Esto sugiere una edad media relativamente alta, es decir que solamente un tercio de los/as estu-

${ }^{22}$ De nuevo, hay que tener en cuenta que $15 \%$ son extranjeros/as. 
¿SOBRAN O FALTAN DOCTORES?

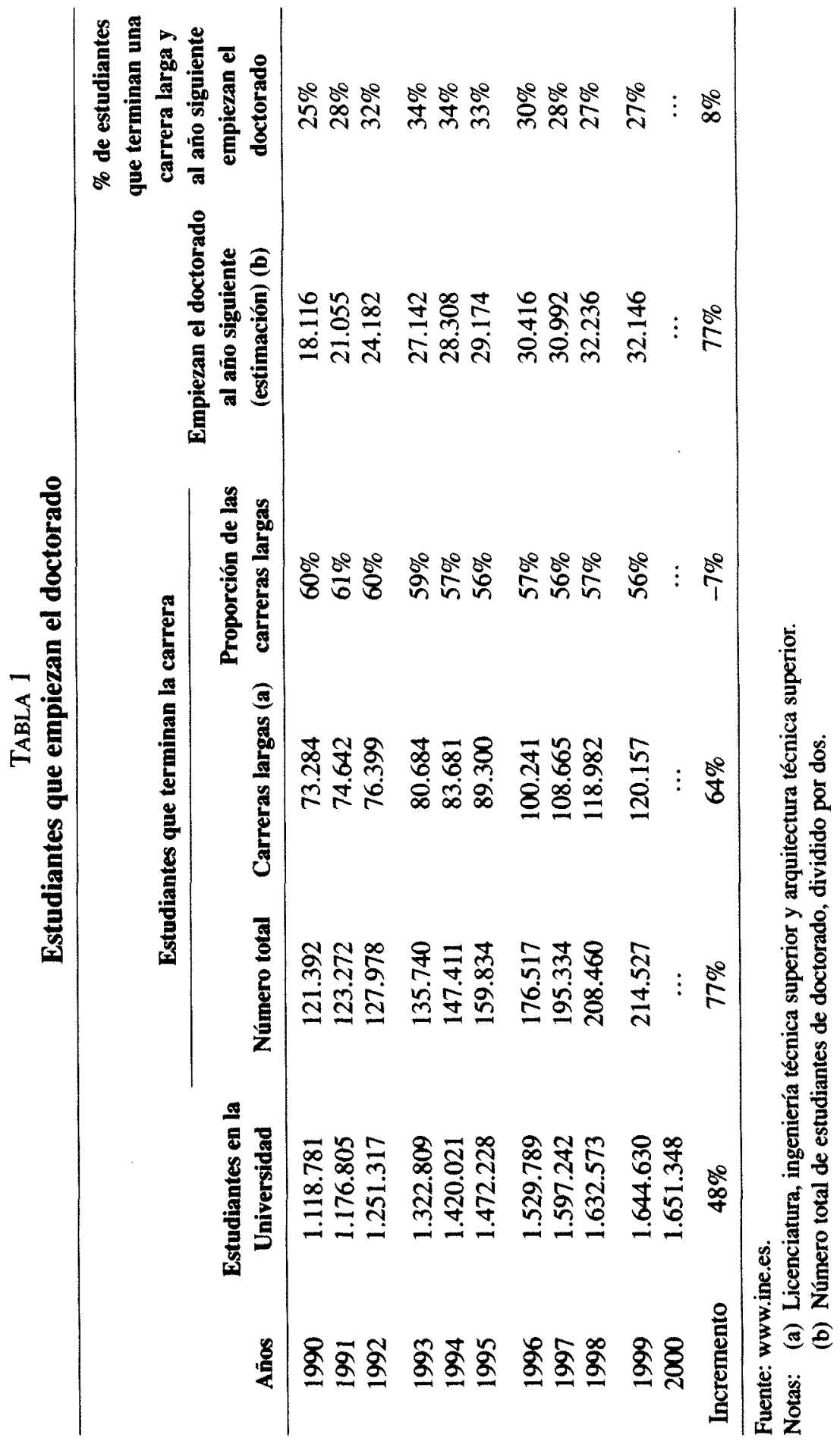


diantes provienen directamente de la carrera (32\% tienen hasta 25 años en 2001). Las estadísticas oficiales incluyen también datos sobre los años transcurridos hasta el inicio de los estudios de doctorado, pero en el $50 \%$ de los casos no consta la información. Eso invalida cualquier conclusión que se quisiera extraer de los datos. De los que se ofrece información, el $48 \%$ empieza el doctorado inmediatamente, es decir sin dejar transcurrir ni un año; y el $24 \%$ espera cuatro o más años. Pero de nuevo, con un porcentaje tan alto de sin respuesta cualquier conclusión es arriesgada. Los datos sugieren que hay dos tipos de estudiantes de doctorado: jóvenes que se matriculan de doctorado nada más terminar sus estudios de licenciatura/ingeniería, y aquellos/as que esperan unos años. Seguramente las motivaciones son diferentes.

Las estadísticas oficiales incluyen también una información limitada sobre trabajo remunerado dentro y fuera de la Universidad de los estudiantes de doctorado (en el año 2001). Son datos para el total de estudiantes matriculados en los dos primeros años de doctorado, que suman 59.123 personas ( $52 \%$ mujeres). Del $29 \%$ de los estudiantes de doctorado no hay información de si trabajan en la Universidad o no. De nuevo, con un porcentaje tan elevado de sin información es arriesgado concluir nada. A riesgo de equivocarnos mucho, si consideramos que del resto tenemos buena información (cosa que no podemos afirmar), aproximadamente el $17 \%$ de los estudiantes de doctorado españoles —uno de cada seis- trabaja en la Universidad: $6,3 \%$ del total son becarios, $5,4 \%$ son profesores, y $1,1 \%$ son personal de administración y servicios (PAS). Hay además un $4,2 \%$ adicional que tiene «otro vínculo» que ignoramos a lo que se refiere. Si el número de becarios (2.654) se pone en relación con el total de estudiantes de doctorado, supone una proporción de becarios realmente baja: $4,5 \%$ del total. Este porcentaje es una de las causas de la baja productividad del doctorado. Las mismas estadísticas dan información muy incompleta sobre trabajo remunerado fuera de la Universidad de los/as estudiantes de doctorado. En este caso no se tiene información sobre $45 \%$ de los/as estudiantes. De los que se tiene información (por lo tanto unas proporciones sesgadas) el 63\% no trabajan, $21 \%$ trabaja en el sector público, y $16 \%$ en el sector privado. Lo más urgente es mejorar estos datos para poder realizar una política de doctorado coherente.

Hay que fijarse que estamos hablando de 32.000 estudiantes nuevos (por lo menos) de doctorado al año en España, que se pueden comparar con los 40.000 nuevos doctores en Estados Unidos al año, un país siete veces mayor, y con diez veces más universitarios. La situación inicial española no puede pues considerarse deficitaria, sino más bien lo contrario. Es un misterio cómo en España un entusiasmo investigador inicial tan elevado produce luego tan poca ciencia. El fracaso está obviamente en el propio proceso de formación investigadora, es decir en los programas de doctorado, que son marginales, endogámicos y con pocos recursos. Demasiados estudiantes empiezan el doctorado, pero muy pocos lo terminan. Nuestra hipótesis es que es el propio sistema el que se autorregula. En la Tabla 2 se puede ver el número de estudiantes que terminan el doctorado. En la década 1990-2000 el número de estudiantes universitarios crece una vez y media, pero el de doctorados aumenta dos veces y media. La tabla presenta los datos del número de estudiantes que terminan el doctorado seis años después, 
¿SOBRAN O FALTAN DOCTORES?

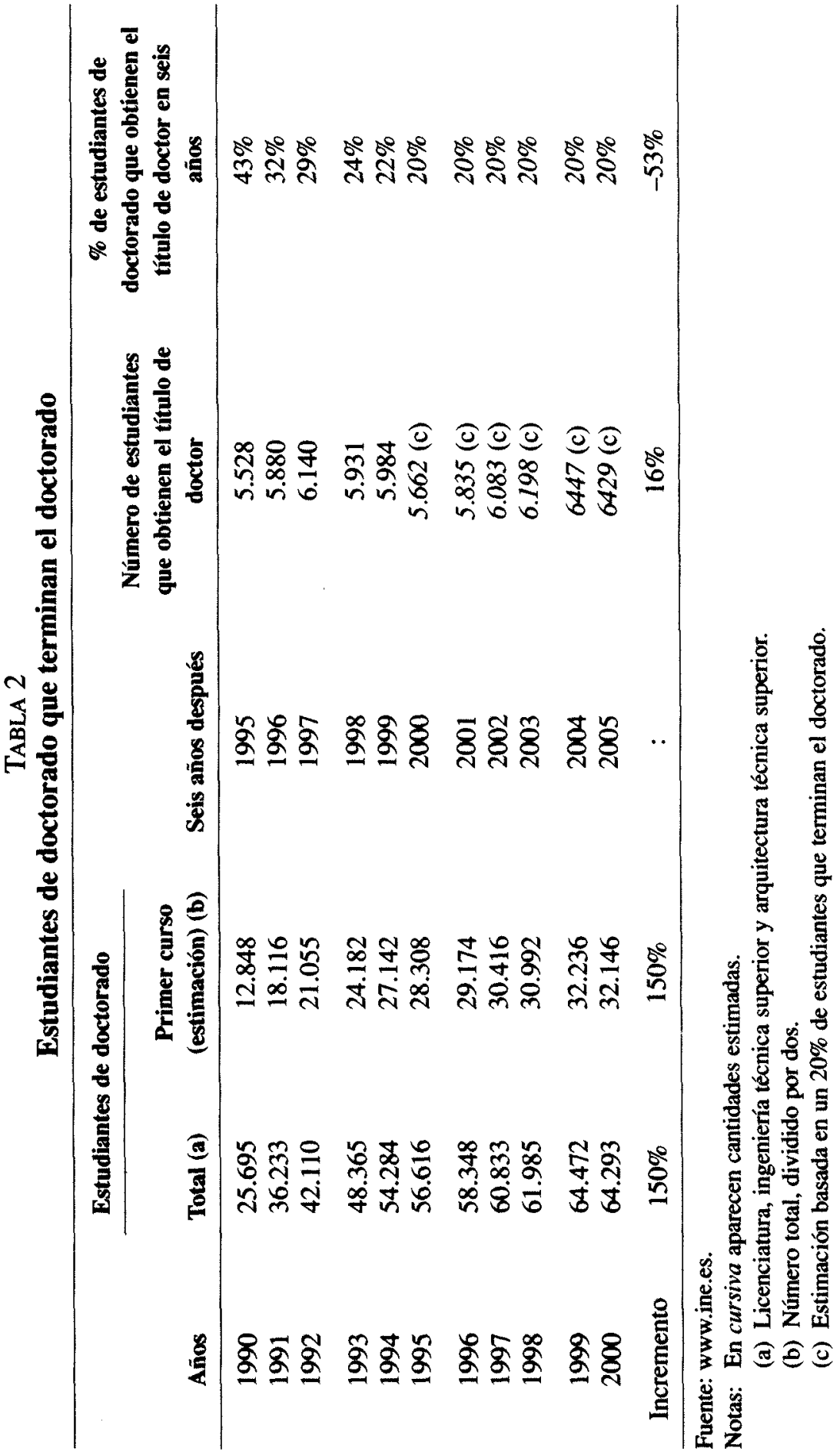


situándose en torno a seis mil cada año. La productividad -medida mediante la proporción de estudiantes de doctorado que obtiene el título de doctor seis años después de haber empezado- desciende abruptamente en esta década: pasa del $43 \%$ al $22 \%$. Cada vez el doctorado es más popular, pero el sistema se autorregula concediendo el título de doctor a una minoría, que progresivamente se fija en torno al $20 \%$. Si se aplicase ese porcentaje a los años venideros, el sistema seguiría produciendo en torno a 6.000 nuevos doctores. Es decir que mientras el número de estudiantes de doctorado aumenta en la década un $150 \%$, la producción real de doctores sólo aumenta un $16 \%$, con lo que en realidad la productividad desciende $(-53 \%)$. El doctorado es pues un sector que no se regula a la entrada sino a la salida. Supone un incremento de esperanzas que luego se ven frustradas. El sistema de doctorado en España requiere pues una reforma drástica y urgente. Pero antes conviene saber qué se puede hacer.

Muchas de esas vocaciones investigadoras son mujeres y extranjeros. Pero sigue habiendo discriminación en cuanto al campo de estudio, lo cual a su vez suponen desigualdades a nivel laboral, y de salario. En el año 2000, el 50\% de los estudiantes de doctorado son mujeres, que suponen el $44 \%$ de los nuevos doctores. En el año 2002, según los datos más recientes, la proporción de estudiantes mujeres aumenta al 53\%. Los extranjeros son el $15 \%$ de los estudiantes de doctorado, el $66 \%$ de ellos/as de América (más bien Latinoamérica). Hay estadísticas nuevas (más recientes) para el año 2001, en donde los extranjeros son solamente $12 \%$. Las estadísticas son poco fiables, y oscilan demasiado para ser creibles enteramente. De 59.123 estudiantes de doctorado (de los dos primeros años del doctorado) hay 6.897 extranjeros. Se ofrecen datos por países, aunque las estadísticas reconocen que del $52 \%$ no consta la nacionalidad. En cualquier caso es indicativo recoger aquí los países extranjeros que tienen más estudiantes realizando el doctorado en España (en cursivas los países de la Unión Europea):

$\begin{array}{ll}\text { México } & 919 \text { estudiantes realizando el doctorado en España. } \\ \text { Colombia } & 729 \\ \text { Brasil } & 613 \\ \text { Chile } & 578 \\ & \\ \text { Portugal } & 555 \\ \text { Marruecos } & 453 \\ \text { Argentina } & 381 \\ \text { Venezuela } & 345 \\ \text { Perú } & 230 \\ & \\ \text { Italia } & 216 \\ \text { Cuba } & 158 \\ \text { Alemania } & 100 \\ \text { Francia } & 96 \\ \text { Estados Unidos } & 75\end{array}$


Las dos terceras partes de los/as estudiantes de doctorado extranjeros son latinoamericanos. Portugal, y ahora Marruecos están participando también bastante. El resto de estudiantes provienen de la Unión Europea. De todas formas la capacidad de atracción de España es bastante limitada en las carreras (licenciatura/ingeniería) pero bastante mayor en el doctorado. Cuando haya estadísticas más precisas será posible realizar un análisis de la influencia real del tercer ciclo español en el extranjero. Pero para ello se requieren también estadísticas de títulos de doctor, que no existen actualmente.

El cálculo de la productividad del doctorado en seis años es realista. Las personas que no obtienen el título de «doctor» en ese plazo es posible que no lo obtengan nunca. Los cálculos sugieren que el rendimiento del doctorado es pequeño y decreciente. El incremento relativo estimado de doctores es nueve veces menor que el de estudiantes de doctorado. Según estos datos, el $20 \%$ de doctores respecto de estudiantes que empiezan (seis años antes) es bajo, pero realista. Supone que termina solamente una de cada cinco personas. Quizás la productividad total sea mayor, porque algunos/as que empiezan el primer curso de doctorado no pasan a segundo curso. Pero es imposible de comprobarlo con los datos que existen actualmente en España. El análisis sugiere que ser estudiante de doctorado y doctor son dos realidades distintas. El sistema se regula por el número de doctores que es muy constante, pero no le importa incrementar el número de estudiantes porque sabe que no van a terminar nunca. El gasto de recursos públicos (la matrícula apenas cubre una décima parte del costo real) y emocionales (de los/as doctorandos y sus familias) es enorme.

\section{4. ¿PROFESORES O INVESTIGADORES?}

No se sabe cómo se contiene la producción de doctores, pues es la suma de muchas decisiones: de cientos de departamentos universitarios, y sesenta universidades. La hipótesis es que se contiene precisamente en base a la demanda de nuevos profesores en la Universidad española. En realidad una proporción de doctores nuevos son ya profesores de la propia universidad. Pero el sistema no se regula de forma precisa, y se producen unos cuantos doctores más que los profesores nuevos que se contratan. Eso supone acumular año a año una bolsa de doctores que no obtienen luego un trabajo académico. La sospecha es que tampoco son asimilados por el sector privado. En una década España produce una bolsa de doctores sin trabajo de al menos 12.000 nuevos doctores que seguramente no han ocupado plaza en la Universidad. El progreso numérico está contenido: en 1990 se produce un/a doctor nuevo por cada 234 estudiantes universitarios, en 1999 es un/a doctor por cada 275 estudiantes. El sistema se contiene mucho - parece que es exitoso en autorregularse- aunque el desequilibrio parece incrementarse cada año.

Los datos exactos se pueden ver en la Tabla 3, que compara doctores nuevos con profesores nuevos de Universidad. Entre los años 1990 y 2000 el número de profesores universitarios crece un $75 \%$. Esto supone una mejora clara de la Universidad española, pues en esos mismos años el crecimiento de estudiantes es del $48 \%$. En la segunda columna se puede ver el incremento anual de pro- 
fesores, contando con factores como abandono del profesorado, mortalidad del profesorado, y jubilaciones. Hay oscilaciones esperables pues hay años con una mayor contratación (como 1991, 1996 y 2000). Aproximadamente oscila entre tres mil y seis mil. Cada vez se contratan menos profesores, siendo el descenso del $22 \%$. En cambio, la producción de doctores es más estable, aumentando sistemáticamente desde alrededor de cuatro mil quinientos hasta seis mil: un incremento del $25 \%$. Si el incremento relativo de profesores es negativo $(-22 \%)$ y el de doctores es positivo $(+25 \%)$ está claro que la desproporción es creciente. Salvo el año atípico de 1991 (en que se contratan dos mil profesores más que los doctores que se producen ese año) en todos los demás años se gradúan más doctores que nuevas plazas de profesor. En una década se acumulan por lo menos 11.000 doctores nuevos que no son absorbidos por el sistema universitario español. En números globales, en una década se crean en España 43.000 puestos nuevos de profesor universitario, y 54.000 doctores nuevos. Si esta tendencia se mantiene en las próximas décadas, se van a crear transformaciones sustanciales en la inclusión de doctores en el mercado de trabajo. Es predecible una expansión de doctores hacia puestos postdoctorales, con becas, trabajos no académicos, y muchos más hacia el sector privado y de la empresa. El doctorado como formación específica para la investigación puede o no cristalizar, o convertirse en un nivel adicional de una carrera profesional ${ }^{23}$.

TABLA 3

Nuevos doctores y profesores de Universidad

\begin{tabular}{ccccc}
\hline Años & $\begin{array}{c}\text { Profesores de } \\
\text { universidad }\end{array}$ & $\begin{array}{c}\text { Incremento anual } \\
\text { de profesores }\end{array}$ & Nuevos doctores & $\begin{array}{c}\text { Número de } \\
\text { doctores menos el } \\
\text { incremento de } \\
\text { doctores }\end{array}$ \\
\hline 1990 & 56.917 & $\ldots$ & 4.776 & $\ldots$ \\
1991 & 63.665 & 6.748 & 4.688 & -2.080 \\
1992 & 67.841 & 4.176 & 4.458 & 282 \\
1993 & 71.297 & 3.456 & 5.193 & 1.737 \\
1994 & 74.251 & 2.954 & 5.157 & 2.203 \\
1995 & 78.193 & 3.942 & 5.528 & 1.586 \\
1996 & 82.951 & 4.758 & 5.880 & 1.122 \\
1997 & 86.362 & 3.411 & 6.140 & 2.729 \\
1998 & 91.168 & 4.806 & 5.931 & 1.125 \\
1999 & 94.344 & 3.176 & 5.984 & 2.808 \\
2000 & 99.619 & 5.275 & $\ldots$ & $\ldots$ \\
Incremento & $75 \%(a)$ & $-22 \%$ & $25 \%$ & $\ldots$ \\
\hline Total de la década & $:$ & 42.702 & 53.715 & 11.512 (b) \\
\hline
\end{tabular}

Fuente: www.ine.es.

Notas: (a) El incremento de estudiantes universitarios es $48 \%$.

(b) Los años no coinciden; la diferencia de totales es 11.013 .

${ }^{23}$ En la reunión del Proceso de Bolonia, en Berlín (septiembre 2003) incluso se habla de dos tipos de doctorado: uno profesional (Dr) y otro académico $(\mathrm{PhD})$. 
La producción de doctores no es igual en todos los sectores o campos del conocimiento. Es imposible realizar un análisis detallado por programas de doctorado, pues faltan los datos oficiales para España. Es posible clasificar el doctorado - tanto estudiantes como doctores nuevos- por grandes campos: ingenierías (incluyendo arquitectura), ciencias experimentales y sanitarias, ciencias sociales (incluyendo derecho y psicología), y humanidades (filosofía, filologías, geografía, historia y bellas artes). En la Tabla 4 se incluye también un detalle de la carrera de medicina que tradicionalmente suponía un tercio de todos los doctorados en el país, y que actualmente ha descendido mucho, pero todavía es un campo específico importante. Como se ha señalado, en la década de los noventa (1990-1999) el incremento en números absolutos de nuevos doctores es del $25 \%$, pero el de estudiantes de doctorado es seis veces mayor.

Más de la mitad de los doctores nuevos obtienen el título en ciencias -experimentales y sanitarias - menos de la cuarta parte en ciencias sociales, un $14 \%$ en humanidades y $11 \%$ en ingenierías. La carrera de medicina doctora al $15 \%$ de todos los nuevos doctores, es decir bastante más que ingenierías o incluso humanidades. La importancia de medicina es paradigmática, contando con que al inicio de la década (en 1990) otorgaba el título de doctor al $32 \%$ de todos los nuevos doctores en España. Sigue pues siendo importante pero ha sufrido un descenso considerable $(-41 \%$ en una década). Por campos de conocimiento, se observa que los cambios son graduales y esperables. Lo que más crece son los doctorados en ingenierías: casi se duplican en una década pasando de 338 a 670 doctores. Algo similar sucede con ciencias sociales que, siendo un grupo numeroso, casi se duplica: pasa de 714 a 1.353 nuevos doctores. Las ciencias, aunque suponen más de la mitad de los doctores en España, apenas se incrementan ya. Las humanidades están en retroceso, descendiendo de 894 nuevos doctores a $844^{24}$. Los incrementos de estudiantes de doctorado y de nuevos doctores no coinciden: lo que más crece es la proporción de estudiantes de doctorado de ciencias sociales, mientras que en nuevos doctores lo que más crece es ingeniería. Por decirlo de otra forma: la productividad de las ciencias sociales es mucho más baja que el resto, situación sólo superada por humanidades cuyos doctorados están en decadencia. En medicina ocurre que la productividad ha disminuido mucho, pues aumenta todavía bastante el número de estudiantes (de doctorado) pero baja mucho la productividad de doctores: de 1.533 a 899 en esa década.

Las transformaciones del sistema de doctorado son pues graduales, pero en las últimas décadas se producen transformaciones decisivas: las ingenierías empiezan a doctorar muchas más personas, con buena productividad; sociales aumenta el número de estudiantes de doctorado pero no tanto el de nuevos doctores, aunque en una década casi duplica el número; ciencias esta

${ }^{24}$ No hay grandes diferencias con Estados Unidos en la distribución de campos. En humanidades es igual (14\%), pero en ingeniería en Estados Unidos es un poco mayor (14\% frente a $11 \%$ en España), y un poco menor en ciencias sociales: $17 \%$ en Estados Unidos y $23 \%$ en España. 
138 JESÚS M. DE MIGUEL, BERNABÉ SARABIA, ELIZABETH G. VAQUERA, HAIZAM AMIRAH

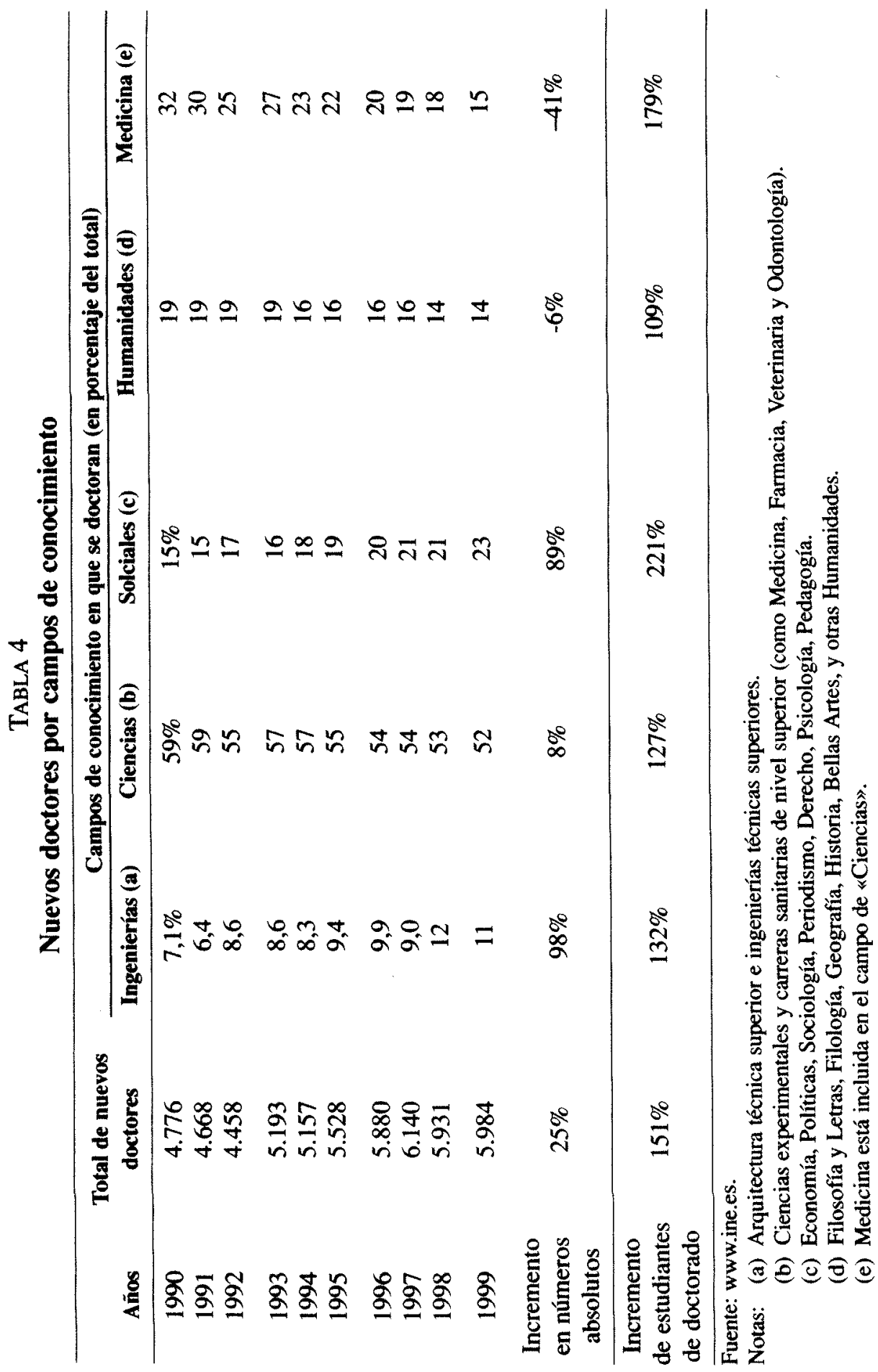


paralizada siendo una cantidad constante, contando con que dentro de ciencias se encuentran los doctorados en medicina que descienden vertiginosamente; y humanidades que de una situación secundaria decrece incluso en números absolutos. Lejos pues la idea de que España cultiva mucho la faceta «humanística» que suele ser un lugar común en muchos de los discursos de rectores y políticos universitarios (De Miguel, 2002a). La investigación en humanidades es reducida, y la formación de doctores/investigadores incluso desciende. La Universidad española - ya de por si demasiado «profesional»- es cada vez más investigadora y tecnológica. La formación de personal investigador se incrementa aunque por debajo de lo necesario para el despegue en I+D del país. La segunda tendencia es hacia la tecnología: cada vez hay más estudiantes y doctores en ingeniería, y su productividad es elevada. Una tercera tendencia es hacia las ciencias sociales, dado que la sociedad es cada vez más compleja y con problemas sociales más difíciles de solucionar. En 1990 los estudiantes de doctorado en ciencias sociales eran el $23 \%$ del total; al final de la década son ya el $30 \%$. Ciencias sociales es el único campo del conocimiento en que aumenta la proporción de estudiantes de doctorado. Pero la productividad de formación de personal investigador en las ciencias sociales es más reducida (la proporción de fracasos es mucho mayor). Medicina, por razones que no tenemos todavía claras, deja de ser el núcleo central de doctorado en España, para reducirse sistemáticamente ${ }^{25}$. En cualquier caso todavía concentra el $15 \%$ del total de títulos de doctorado. No puede pues hablarse del doctorado como una entidad unívoca. Las áreas de conocimiento se expanden y se diversifican. También el capital humano es diferente.

\section{PROCESOS DE DEMOCRATIZACIÓN Y FEMINIZACIÓN}

La expansión de la Universidad, y del número de jóvenes estudiando a pesar de que las cohortes se reducen sistemáticamente (debido a la bajada de natalidad dos décadas antes), lleva seguramente - no tenemos datos-a que más personas de clases bajas realizan carreras universitarias largas, e incluso realizan luego el doctorado. La Universidad se democratiza... y también el doctorado. El proceso más claro es el de feminización. En los países avanzados cada vez hay más mujeres en la Universidad, hasta el punto de que superan ampliamente a los varones. Eso va a producir transformaciones sociales considerables. En España, en las carreras universitarias hay ya un 53\% de mujeres, pero acaban los estudios bastantes más: 59\% de mujeres. Además la mujer obtiene mejores notas. Por eso, el número de mujeres que potencialmente pueden seguir estudios hacia el doctorado, y obtener becas, es mayor. En el año 2000, por primera vez en la historia de España, la proporción de

${ }^{25}$ Algunas razones pueden ser: cuotas de doctorado o simple disminución del estudiantado de la carrera por el numerus clausus; actualmente no tanta gente desea ser médico; la profesión ha perdido prestigio y además se ha feminizado; quizás los mejores se van al extranjero; el doctorado ha dejado de ser una alternativa interesante. 
mujeres entre los estudiantes de doctorado alcanza el 50\%. En el año 2002 sube al $53 \%$. La producción de doctoras es $44 \%$ en el año 1999, llegando al $49 \%$ dos años después. No puede ya hablarse de discriminación de la mujer en la Universidad, ni siquiera en el doctorado (Vaquera y De Miguel, 2001). Otra cosa es que la proporción de mujeres en el profesorado universitario sea solamente del 34\%. Pero en lo que atañe al presente artículo, no existe ya discriminación, y es muy posible que en el futuro la situación sea la inversa (falta de varones). En la Tabla 5 se observa que todavía hay una discriminación clara en ingeniería (arquitectura e ingenierías técnicas superiores). Tanto en estudiantes como en nuevos doctores, en ingeniería la mujer es solamente una cuarta parte del total (26\%). En el resto de los campos científicos son más las mujeres estudiando doctorado, especialmente en humanidades (56\%) pero incluso en ciencias (53\%). Las proporciones de mujeres entre los títulos de doctor respectivos es un poco menor (entre $43 \%$ y $48 \%$ ) debido a que corresponden a cohortes anteriores en donde todavía existía discriminación contra la mujer.

TABLA 5

Proporción de mujeres por campos de conocimiento

\begin{tabular}{ccc}
\hline & \multicolumn{2}{c}{ \% de mujeres del total de: } \\
\cline { 2 - 3 } Campos de conocimiento & $\begin{array}{c}\text { Estudiantes de doctorado } \\
\text { (en 2000) }\end{array}$ & Nuevos doctores (en 1999) \\
\hline Ingenierías & $26 \%$ & $26 \%$ \\
Ciencias & 53 & 46 \\
Sociales & 52 & 48 \\
Humanidades & 56 & 43 \\
Total & $50 \%$ & $44 \%$ \\
(Número) & $(64.293)$ & $(5.984)$ \\
\hline Año 2001-2002 & $52,5 \%(a)$ & $49,1 \%$ \\
\hline
\end{tabular}

Fuente: www.ine.es.

Nota: (a) En estudiantes de carrera es $53,4 \%$ de mujeres, y en estudiantes que terminan la carrera es $58,5 \%$ de mujeres.

Ingeniería es todavía un feudo masculino ${ }^{26}$. No lo es tanto Arquitectura (que tiene un $32 \%$ de tesis realizadas por mujeres), pero lo es mucho Electronica (9\%), Telecomunicaciones (sólo 13\% de doctoras mujeres), o Caminos, Canales y Puertos $(22 \%)$. Estas carreras son las que más van a tener que cambiar para excluir la discriminación. En el resto de carreras se ha logrado casi la paridad. En Ciencias la participación de la mujer en los doctorados de

${ }^{26}$ Lo es más aún en Estados Unidos, pues doctora sólo a un $17 \%$ de mujeres (frente a $26 \%$ en España). En cambio otros sectores están más feminizados: $54 \%$ de mujeres doctoras en ciencias sociales (versus $48 \%$ en España), o $51 \%$ en humanidades (43\% en España). La estructura es pues similar entre los dos países, con algunas tendencias dispares. 
Medicina todavía es baja (42\%), pero bastante alta en Farmacia (59\%). En cualquier caso las profesiones sanitarias se están feminizando, incluso Veterinaria (49\% de doctoras). Las ciencias sociales no se configuran como las carreras más femeninas - son las humanidades - pero son las que consiguen que más mujeres se doctoren: $48 \%$. En Psicología se llega a un $61 \%$ de mujeres. Pero incluso en Sociología las mujeres todavía no alcanzan la mitad de los títulos de doctor $(46 \%)$, siendo una proporción menor en Económicas (43\%). Este último porcentaje es el que alcanzan las Humanidades, en donde hay carreras bastante de mujeres (Historia del Arte con $71 \%$ de doctoras) y otras carreras más bien de varones (Filosofía con solamente un 38\% de mujeres entre los doctores nuevos, Antropología con 36\%, Geografía con $21 \%$ y Teología con $4 \%$ de mujeres). No todas las Humanidades son pues un feudo femenino, sino que suponen un panorama diverso.

La evolución es clara en el año 2002: hay un 53\% de mujeres que estudian la carrera, pero como obtienen mejores notas y abandonan menos la carrera, entre las personas que terminan la carrera las mujeres son el $59 \%$. En doctorado hay un $53 \%$ de mujeres, pero disminuyen al $49 \%$ entre los nuevos títulos de doctorado por causa de las cohortes. En estos cuatro grupos las mujeres abundan más en el sector público (que en el privado). Así en estudiantes de carrera son mujeres $53,6 \%$ en universidades públicas y 50,3 en privadas; terminan la carrera $58,8 \%$ en pública y $55,6 \%$ en privada; estudian doctorado $52,7 \%$ en pública y $46,6 \%$ en privada; y terminan el doctorado obteniendo el título de doctor $49,2 \%$ mujeres en pública y $46,6 \%$ en privada. Aunque las diferencias no son grandes, sí son consistentes. La discriminación sigue pues siendo económica incluso cuando se tiene en cuenta el género. La Universidad pública cumple más una función social. La proporción de extranjeros entre los estudiantes de doctorado en España es el 14,8\%, un porcentaje que sigue creciendo. Pero aquí es al revés; hay más extranjeros en el sector privado $(24 \%)$ que en el sector público (14\%). No debe ser una explicación de servicio público, sino de negocio privado ${ }^{27}$.

\section{DIFERENCIAS POR COMUNIDADES AUTÓNOMAS}

Un aspecto importante de la desigualdad en la producción de doctores son las diferencias regionales. El estudio de las tasas en las diecisiete Comunidades Autónomas españolas explica algunas de las carencias más importantes del sector universitario. En un estudio previo sobre la Calidad de las universidades españolas y sistema universitario de las Comunidades Autónomas (De Miguel, Caïs y Vaquera, 2003) - realizado entre la Universidad de Barcelona y la University of Pennsylvania - se analizan las diferencias existentes en la organización universitaria de las 17 Comunidades Autónomas españolas. Las diferencias en la producción de tesis doctorales son considerables.

${ }^{27}$ Sobre las relaciones entre las universidades latinoamericanas y las españolas se puede ver Fundación Santander Central Hispano, 2001. También la recensión (DE MIGUEL, 2002a) 
En el total de España se producen unas cuatro tesis doctorales por cada mil estudiantes universitarios. Pero en Navarra (Comunidad Foral de Navarra) son casi diez, y en La Rioja no llega a media. La tasa de tesis doctorales es pues un indicador excesivamente variable, que no homogeneiza a las Comunidades Autónomas, sino todo lo contrario:

Madrid

Navarra

País Vasco

Cataluña

Baleares

La Rioja

Aragón

Canarias

Cantabria

Comunidad Valenciana

Castilla y León

Asturias

Murcia

Galicia

Castilla-La Mancha

Andalucía

Extremadura

Total de España
5,7 tesis doctorales por mil estudiantes.

9,8

2,4

4,8

1,9

0,4

4,3

3,5

4,3

4,0

3,4

3,9

4,4

2,9

0,8

3,4

2,7

3,8

El total de España incluye las tesis doctorales de la Universidad Nacional de Educación a Distancia (UNED) que tiene una tasa de 0,8. Las diferencias pues entre Comunidades Autónomas son enormes, de veinticinco veces. Las Comunidades Autónomas en esta lista están ordenadas por niveles de riqueza (PIB per capita), pudiéndose observar que la producción de tesis no depende enteramente del nivel de desarrollo económico de la región. El País Vasco tiene un nivel bajísimo de producción de tesis doctorales (63\% de la media nacional), algo que puede estar relacionado con la situación política existente a pesar de que el sector de $\mathrm{I}+\mathrm{D}$ ha sido tradicionalmente extenso en esa Comunidad Autónoma. Madrid (50\% más que la media) y Barcelona ( $26 \%$ más que la media) están en situaciones ventajosas que son esperables. En un contexto de otras carencias Murcia tiene una buena Universidad ( $16 \%$ mejor que la media). Pero es cierto que las cuatro Comunidades Autónomas más pobres tienen una productividad baja de nuevos doctores, sobre todo Castilla-La Mancha. La riqueza es un factor que explica en parte la productividad de títulos de doctor en cada región, a pesar de la situación tan carencial de País Vasco y de Baleares, 
zonas donde a pesar del desarrollo económico la investigación universitaria no parece florecer. En el País Vasco las universidades tienen poco capital humano: poco profesorado y poco PAS (personal de administración y servicios). En cambio en Baleares no es esa la explicación, sino una falta generalizada de productividad. En el otro extremo la buena situación de Murcia no se explica por el resto de la organización de la Universidad (que tiene carencias obvias como se observa en Excelencia) sino que se especializa bastante en doctorado, siendo además productiva en ese tercer ciclo. Las Comunidades Autónomas menos ricas tienen tasas bajas de nuevos doctores, pero no son peores que en otros indicadores. Salvo Murcia y Canarias, la producción del doctorado se concentra en el norte de la península, sugiriendo así que es un tema de seniority. Las regiones y universidades con solera producen más doctores, algo que ya se sugiere en nuestro libro Excelencia (2000).

Los autores del presente artículo han estudiado con más profundidad las relaciones entre estas variables, asociando los resultados en coeficientes de correlación. Si se tienen en cuenta todas las universidades españolas (públicas y privadas), la producción de doctores se explica fundamentalmente por la tasa de profesorado existente (correlación de 0,59 ), y en parte también por la tasa de PAS $(0,40)$, pero no tanto por la riqueza de la región medida según el PIB per capita (correlación de 0,25), ni tampoco mucho por la antigüedad de la universidad $(0,22)$. Recursos y antigüedad tienen una cierta influencia positiva. Lo importante es tener un profesorado abundante y bien preparado. La proporción de mujeres-profesoras no explica $(-0,02)$ la productividad de doctores. Para las universidades públicas la riqueza (correlación 0,27$)$ y la antigüedad de la universidad $(0,31)$ son más importantes, mientras que son menos importante el profesorado $(0,39)$ o el PAS $(0,29)$. La existencia de mujeres-profesoras sigue siendo un factor incluso más negativo $(-0,03)$. La variable que explica mejor la producción de doctores es el gasto por estudiante universitario (correlación de 0,40 ). Las universidades con más dinero consiguen también doctorar a más estudiantes. Los recursos económicos es la variable explicativa más contundente.

Las diferencias en cuanto al número de investigadores que existen en las universidades de las Comunidades Autónomas son enormes. La media española es de 2,7 investigadores universitarios por cada cien estudiantes. Pero las diferencias son de 3,4 veces: 5,4 investigadores (por cada cien estudiantes) en la Comunidad Foral de Navarra y 1,6 en Castilla-La Mancha. Es decir, las diferencias en la producción de doctores son enormes ( 25 veces) pero no así en la tasa de investigadores en la Universidad ( 3 veces). Como hemos sugerido antes, es posible que los doctores nuevos no se dedican necesariamente a la investigación en esa Comunidad Autónoma, o que no lo hagan en la Universidad. Cuanto más desarrollada es una región más posible es que los nuevos titulados doctorales vayan a trabajar a la empresa privada. La distribución por Comunidades Autónomas es similar en cuanto a sus tendencias (siempre refiriéndose a la Universidad): 


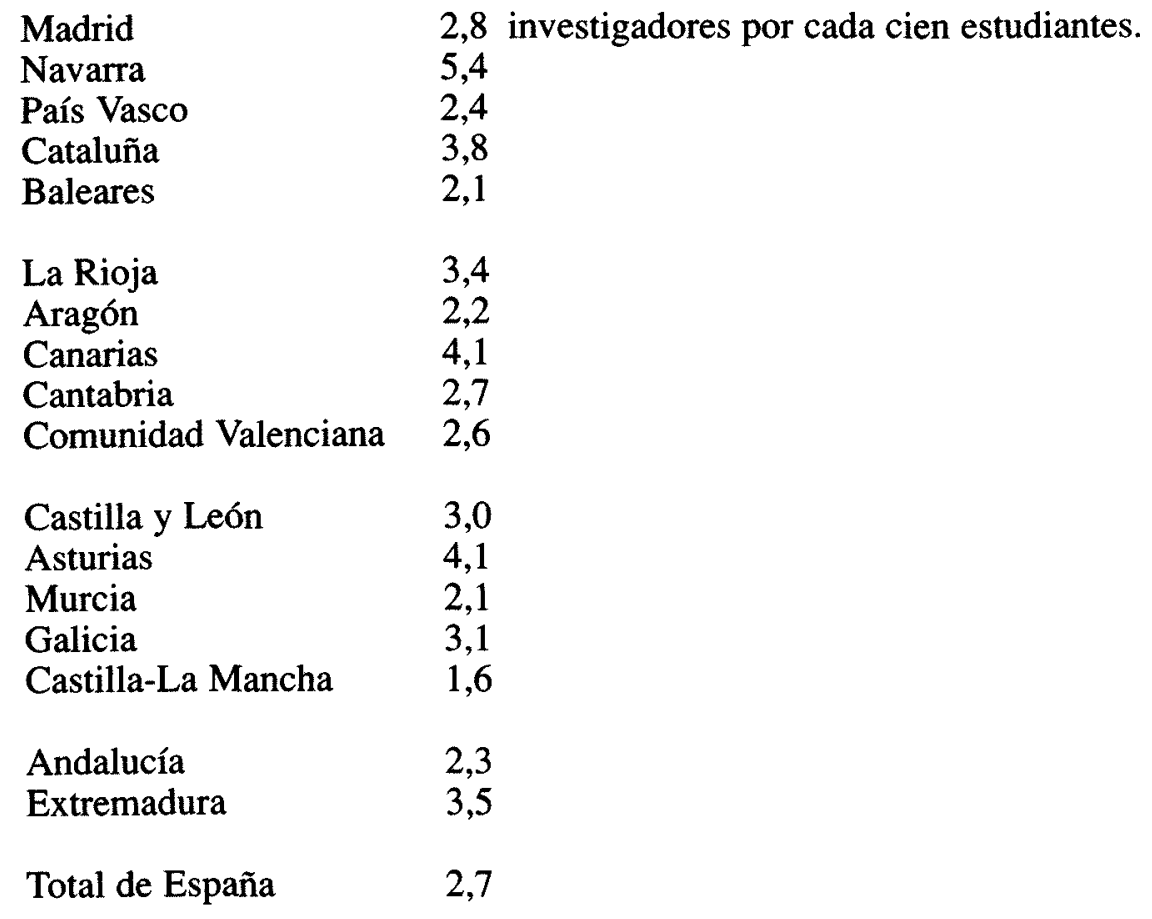

La situación del País Vasco sigue siendo más baja de lo esperable para su nivel global de desarrollo. También la de Baleares cuya insularidad produce un cierto brain drain. Pero La Rioja o Extremadura están bastante por encima de la media. Asturias y Canarias destacan por sus niveles de investigadores en la Universidad. Madrid apenas supera la media nacional, aunque se sabe que la Comunidad de Madrid concentra una gran parte del I+D de toda España, tanto en recursos como en investigadores: tiene 2,4 veces más recursos de I+D per capita que la media nacional, y 2,1 veces más investigadores por población. Madrid tiene, por ejemplo, 40 investigadores por millón de habitantes, mientras que la media española es 19. Sin embargo, sus universidades están en situación relativamente baja con un gasto en I+D que apenas es un $11 \%$ más que la media nacional, y un $4 \%$ más investigadores. Sin embargo, las universidades madrileñas producen un $50 \%$ más doctores cada año que la tasa media nacional. Esta sobre-producción de doctores es absorbida por otros sectores y empresas (quizás también por otros países, en el caso de titulados extranjeros).

Las diferencias no son fácilmente explicables, y tampoco dependen de la productividad del doctorado. Se explican más bien por el profesorado que correlaciona 0,77 con el personal investigador de las universidades; en realidad son las mismas personas. Las universidades buenas producen más investigadores (y viceversa). En nuestro libro de Excelencia (2000) la correlación entre investigadores en el sistema universitario de la Comunidad Autónoma y la nota de ranking de sus universidades (dentro de la misma Comunidad Autó- 
noma) es 0,65 . La calidad global de las universidades es el factor que explica mejor la existencia de investigadores en la Universidad. Pero se observa que cuando la proporción de las universidades de una Comunidad Autónoma en el gasto total en I+D (de esa Comunidad) es baja entonces hay más investigadores en la Universidad (correlación de -0,02). Cuando la universidad es muy importante en el desarrollo investigador de la región, entonces no tiene mucha dotación de capital humano. Quizás porque entonces ambos factores dependen de la falta de $\mathrm{I}+\mathrm{D}$ generalizada. El gasto en $\mathrm{I}+\mathrm{D}$ y el personal de investigación de las universidades correlaciona positivamente - lo contrario sería absurdopero no es una correlación excesivamente alta $(0,39)$. Lo que sugiere que investigar y la existencia de recursos para investigar son fenómenos relativamente independientes. Si esto se añade a lo ya comprobado de que tesis doctorales e investigadores tienen poco que ver, sugiere una organización extraña de la investigación universitaria en España. La solución es tener mejores programas de doctorado, pero que los/as doctores luego realmente investiguen, y tengan financiación y recursos suficiente para hacerlo. Los indicadores son un poco independientes unos de otros. El mejor factor explicativo es tener universidades bien dotadas de recursos generales y de personal (sobre todo profesorado pero también PAS).

Las diferencias entre Comunidades Autónomas son enormes y a menudo inexplicables. No parece que eso preocupe mucho al Gobierno central (ni a los autonómicos), ni existen planes generales de convergencia en el tema de doctorado. La primera ley autonómica - la Ley de Universidades de Cataluña, LUC - supone una falta de solidaridad llamativa (De Miguel, 2004b). Comunidades Autónomas que continuamente llaman la atención sobre su situación, y se presentan como modelos (como suele ser el caso de Madrid, Cataluña y del País Vasco) cuando se miden sus datos de productividad no son todos ejemplos de productividad ni de calidad. Especialmente la situación del País Vasco en el contexto español es lamentable. La falta de datos comparativos encubría hasta ahora la ignorancia sobre la productividad diferencial de las Comunidades Autonomas. Es pues necesaria una política efectiva de solidaridad interterritorial, que supere el egoísmo de las Comunidades Autónomas.

Las universidades españolas tienen globalmente 2,7 investigadores por cada cien estudiantes universitarios, y las diferencias por Comunidades Autónomas son elevadas: 3,4 veces. Esto supone un nivel de desigualdad bastante mayor que las diferencias de riqueza, que son de 2,1 veces (medida en PIB per capita) que oscila entre 18,9 miles de $€$ en Madrid, y 9,1 en Extremadura. Cada año a esos 2,7 investigadores se le suman 0,4 doctores nuevos de los cuales aproximadamente la mitad encuentran trabajo en la Universidad de la misma Comunidad Autónoma. Pero en la producción de doctores las diferencias entre las Comunidades Autónomas son enormes: de 25 veces. La producción de doctores no está planificada, pero luego el sistema universitario se autorregula, contratando solamente aquellos/as investigadores que necesita para sus universidades, aunque la distribución final sigue siendo demasiado desigual. La Universidad absorbe al 55\% de los/as investigadores existentes en España, aunque sólo cuenta con el 30\% del presupuesto de I+D 
total. La productividad de 0,4 doctores adicionales cada año — por cada cien estudiantes que medíamos antes- son absorbidos por la propia Universidad en un poco más de la mitad de los casos, de media en el 55\%. El resto, $45 \%$, trabajan en la Comunidad Autónoma como investigadores pero en otras instituciones públicas o privadas. Desgraciadamente, no tenemos estudios longitudinales que sigan la vida de esos doctores/investigadores, por lo que es difícil concluir con proposiciones exactas sobre la realidad. Con el paso de los años, se produce una distribución diferente de investigadores que trabajan en cada Comunidad Autónoma como puede verse en la distribución actual del número de investigadores por diez mil habitantes:

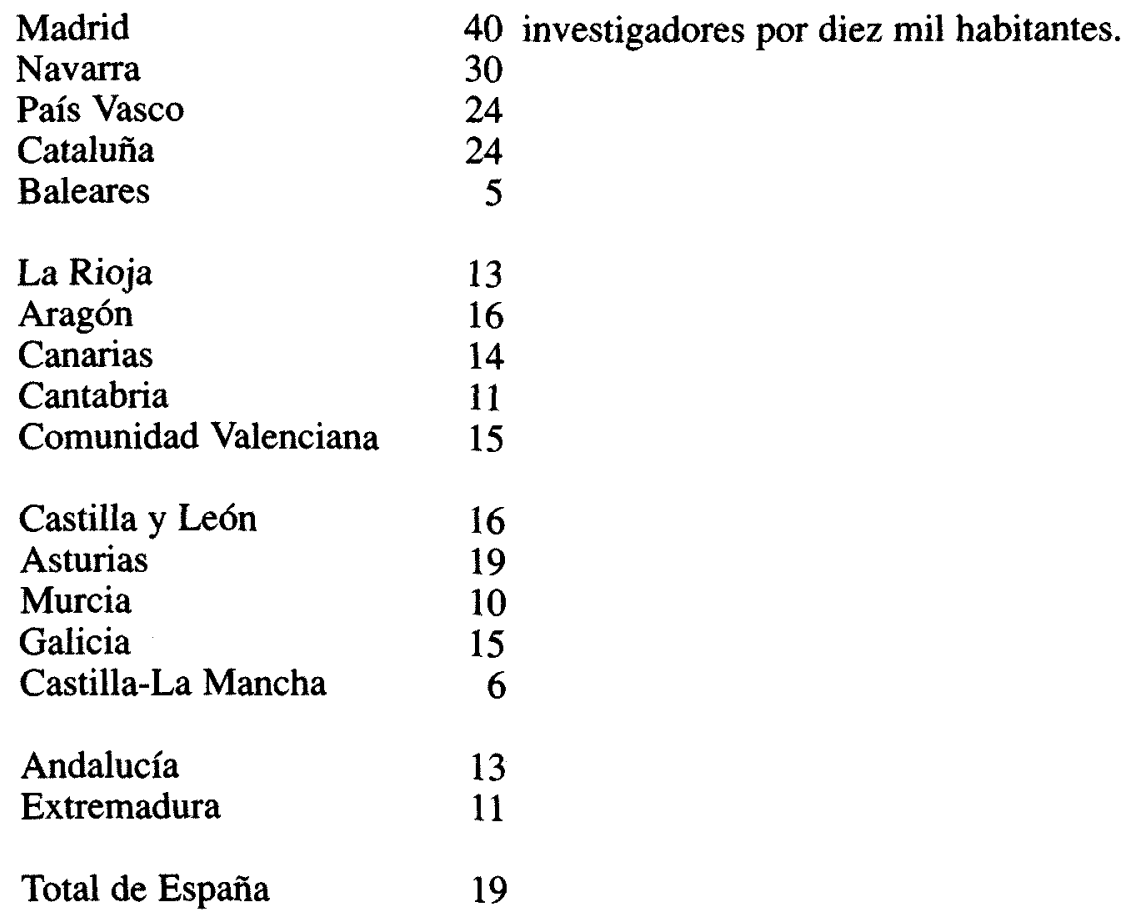

La tasa de investigadores depende bastante del desarrollo económico de la Comunidad Autónoma; es posible que también suceda al revés. Salvo el caso de Baleares, el núcleo fuerte de investigación se produce en las Comunidades Autónomas más ricas. En este caso la situación desfavorable del País Vasco no es tan evidente; incluso tiene más investigadores que Cataluña. La crisis en el País Vasco se centra primordialmente en la Universidad. Las diferencias en la tasa de investigadores por Comunidades Autónomas son de 7,6 veces, es decir más del doble que las diferencias de investigadores en las universidades de esas Comunidades Autónomas, y además mucho mayores que las diferencias de riqueza global que son de 2,1 veces. Se puede suponer que las diferencias excesivas ( 25 veces) en la producción de doctores entre las Comunidades Autónomas terminan produciendo por acumulación las diferencias 
geográficas de investigadores (diferencias de 7,6 veces), pero el sistema universitario se autorregula bastante (pues incluye sólo 3,4 veces de diferencia $^{28}$. Las Comunidades Autónomas productoras de títulos de doctor (Navarra, Madrid, Cataluña, Murcia, Cantabria) no coinciden exactamente con las que tienen más investigadores globalmente (que son Madrid, Navarra, País Vasco, Cataluña, Asturias). Eso sugiere que ha habido variaciones en las últimas décadas, o simplemente que hay un cierto trasvase o movilidad geográfica de nuevos doctores ${ }^{29}$.

No existe una planificación de la producción de doctores en España, ni siquiera a nivel de Comunidades Autónomas. El sistema universitario se regula absorbiendo al 55\% de los/as investigadores, y acumulando el excedente de doctores en las Comunidades Autónomas más ricas (a excepción de Baleares, cuyo desarrollo económico es alto pero su sector de $\mathrm{I}+\mathrm{D}$ es extraordinariamente bajo). Las diferencias de investigadores que son de 7,6 veces, reflejan a su vez las diferencias de gasto en $I+D$ per capita que son igualmente desiguales $(8,1$ veces entre Madrid y Baleares). La riqueza de las Comunidades Autónomas explica el gasto per capita en I+D (la correlación es 0,75 ) lo que seguramente supone una relación causal en ambas direcciones. La tasa global de investigadores es un factor que explica menos estas desigualdades (correlación 0,69 ). La riqueza correlaciona negativamente con la importancia de la Universidad en el sistema de I+D: cuanto más rica es la región menos gasto relativo en $I+D$ concentra la Universidad (correlación $-0,50$ ) y sobre todo menos investigadores tiene proporcionalmente $(-0,58)$. En las Comunidades Autónomas más ricas, la producción de títulos de doctor es absorbida en mucha mayor proporción por instituciones externas a la Universidad. Pero en cualquier caso, el desarrollo económico de la región sigue estando asociado al gasto en I+D que se realiza en la Universidad de esa Comunidad Autónoma $(0,51)$ pero ya no tanto la tasa de investigadores dentro de la Universidad (correlación de 0,25 ). La importancia relativa de la Universidad es menor en las zonas más ricas, y sobre todo atrae menos a investigadores.

El sistema de doctorado en España produce un trasvase de títulos de doctor hacia las zonas más desarrolladas, y en esos casos fuera de la Universidad. En cualquier caso las enormes diferencias ( 25 veces) en la producción de doctores no son fácilmente equilibrables por el sistema, acumulando desigualdades en vez de redistribuir el capital humano. Es significativo que la relación entre gasto en I+D per capita y tasa de investigadores correlaciona 0,94 a nivel de todo el sector por Comunidades Autónomas, pero solamente 0,39 en el caso de las universidades de esas mismas Comunidades Autónomas. El sis-

${ }^{28}$ En otros recursos las diferencias son en torno a tres veces. Por ejemplo en libros de biblioteca por estudiante, las diferencias entre los sistemas universitarios de las Comunidades Autónomas es de 2,8 veces: de 37 libros por estudiante en la Comunidad Foral de Navarra a 13 en Andalucía o Extremadura. En este caso Baleares se encuentra en una situación favorable: un $70 \%$ más que la media nacional de 17 libros por estudiante.

${ }^{29}$ La situación muy favorable de la Comunidad Foral de Navarra se debe en gran parte a la influencia de la Universidad de Navarra que doctora a 3,8 veces más estudiantes que la media nacional (y 4,1 más veces que la media de las universidades privadas españolas). 
tema es racional si se estudia globalmente, pero no parece serlo dentro de la Universidad. El gasto en I+D depende bastante de la riqueza global de cada Comunidad Autónoma pero no así la producción ni la contratación de doctores. La falta de planificación, y la carencia de datos - y de estudios- esconde desequilibrios enormes en este sector, y situaciones de precariedad en las universidades de ciertas Comunidades Autónomas. La falta de una correlación alta entre el gasto en I+D y la tasa de investigadores en la Universidad (en las 17 Comunidades Autónomas) sugiere que muchos investigadores universitarios están investigando sin recursos, o que bastantes personas que se etiquetan como «investigadores» no lo son. Creemos que ésa es la explicación de la falta de correlación entre gasto e investigadores.

\section{DISCUSIÓN DE LOS DATOS}

Los datos oficiales sobre doctorado en España son confusos y equívocos. El Instituto Nacional de Estadística -y el Ministerio de Educación, Cultura y Deporte - publican datos generales, sin distinguir cursos, y con pocas variables. Sólo en algunos casos hay clasificaciones interesantes, pero con un porcentaje excesivo de casos sin información, que en algunas situaciones llega hasta la mitad. La validez de esos datos es baja. Por otro lado, si se quiere comparar la situación española con otros países es casi imposible. Las estadísticas mundiales de la UNESCO, OCDE, e incluso las de Eurostat no dan datos fiables sobre doctorado, ni sobre tesis doctorales. No hay pues tampoco estadísticas internacionales comparables. Los últimos datos sobre doctorado en Estados Unidos son interesantes y fiables, pero la realidad social y universitaria de ese país es diferente. En el presente artículo hemos presentado algunos datos comparables. Somos conscientes de las limitaciones del presente análisis. El doctorado es un tema sobre el que se ha escrito poco; apenas hay investigación empírica sobre la investigación.

La pregunta original de la investigación es ¿Sobran o faltan doctores? La respuesta es las dos cosas. Muchas personas empiezan los estudios de doctorado, pero muy pocos obtienen el título de doctor. Sobran porque se producen más de los que absorbe el sistema; faltan porque luego no se dedican a la investigación. Nuestra hipótesis principal es que el sistema español de producción de doctores se autorregula, pero lo hace de forma deficiente: (a) crea una bolsa de doctores sin empleo que crece cada año, y (b) logra la estabilidad relativa gracias a un coste humano y de recursos enorme. Se convierten en doctores aquellas personas que ya no tienen más remedio que conseguir el título si quieren conservar su puesto de trabajo (y no todos/as). En España es usual estudiar el doctorado en la misma universidad donde se trabaja, y requerir el doctorado para estabilizar su puesto de trabajo docente, o para poder promocionar a un puesto a tiempo completo y con seguridad en el empleo. Se convierten pues en doctores los que ya son profesores y no lo contrario. Esta situación va unida a una falta de movilidad geográfica llamativa. Las universidades no forman doctores (o investigadores) para un mercado de trabajo 
abierto, sino sobre todo para sí mismas. La Universidad española concentra al $55 \%$ de los/as investigadores españoles, con el $30 \%$ de los recursos de I+D. Cada universidad tiene sus programas de doctorado suficientes para cubrir las plazas de profesorado nuevas en todas las áreas de conocimiento ${ }^{30}$. La LRU (Ley de Reforma Universitaria) de 1983 generó una endogamia alta en la Universidad española, con una movilidad del profesorado mínima. Con la LOU (Ley Orgánica de Universidades) de 2002 se pretende solucionar esta situación, pero la tendencia a la endogamia es todavía fuerte. Apenas hay programas de doctorado que formen doctores para otras universidades o centros.

El sistema se autorregula, pero produce (¿por equivocación? ¿como seguridad?) un exceso de doctores cada año, que no son asimilados como profesores ni investigadores en el sector académico: tanto en universidades públicas como en universidades privadas, Consejo Superior de Investigaciones Científicas, y organismos similares. La bolsa de doctores sin empleo aumenta cada año al menos desde la década de los noventa del siglo pasado. Calculamos que se produce un exceso de unos/as once mil doctores cada década. Esto puede llevar a una cierta presión en el sector privado (empresarial) para que contrate investigadores (doctores), pues esa es una de las deficiencias españolas del sector de I+D. Pero no se está consiguiendo.

Realmente sólo terminan «los que tienen que terminar» (son cada vez más mujeres) y pueden ser asimilados por los Departamentos, o ya lo han sido previamente. Si terminasen los que empiezan, o un $80 \%$ de los que empiezan, en un plazo de seis o siete años, España estaría produciendo tantos doctores como Estados Unidos, que tiene una población siete veces mayor, con diez veces más estudiantes universitarios, y que además forma a la elite de doctorado del mundo (un tercio son extranjeros). Dado que, a pesar de ser un sistema eminentemente público, España no regula ni planifica la producción de doctores la falta de coordinación y el malgasto de recursos es considerable. La autorregulación - sin ningún tipo de planificación central ni autonómica - produce que cada año haya más personas empezando el doctorado, y proporcionalmente menos personas terminándolo. La productividad es alrededor de uno de cada cinco estudiantes. El coste material (en recursos universitarios) y personal (los/as propios estudiantes de doctorado que nunca logran el título) es enorme.

España a pesar de producir muchos doctores (ergo investigadores) tiene unos niveles muy bajos de $\mathrm{I}+\mathrm{D}$, aproximadamente entre la mitad y la tercera parte de lo que debiera según su nivel de desarrollo. En muchos indicadores España se iguala a la media de la OCDE, sin embargo en I+D medido como gasto proporcional (al PIB) es la mitad de la media de la OCDE. España tiene un exceso de estudiantes de doctorado, pero muy pocos (aunque todavía más de los necesarios) obtienen el título de doctor. Pero luego estos doctores no

${ }^{30}$ En España actualmente el profesorado (y el personal investigador) está dividido en áreas de conocimiento. Una universidad grande puede llegar a tener un centenar de departamentos, cubriendo la mayoría de áreas de conocimiento. Oficialmente en España hay 187 «áreas de conocimiento». 
realizan apenas investigación. Por eso a la pregunta de si sobran o faltan doctores en España la contestación es las dos cosas. Sobran pues se produce un exceso de doctores que encuentran dificultades para encontrar trabajo a su nivel; pero faltan doctores que realmente realicen investigación. El problema más angustiante es cómo conseguir que los nuevos doctores sigan investigando e innovando. No queda claro si se forman como doctores sin intención de investigar, o si la estructura académica les impide luego realizar investigación sustantiva. El sector universitario español parece incapaz de solucionar este problema. La falta de investigación - y de Ciencia - en España es una polémica de siglos. Se pensó que con producir doctores ya estaba arreglado el problema... pero esos doctores luego no ejercen como tales, ;no investigan! Las Comunidades Autónomas, una detrás de otra, han intentado superar este problema, pero empeoran la situación creando una red de supuestos investigadores endogámicos que impiden la entrada a las universidades a cualquiera que se haya doctorado fuera. También se crean evaluadores locales que defienden ferozmente el inmovilismo profesional, en algunos casos encubierto en forma de nacionalismo lingüístico.

La tensión entre gasto y calidad en las universidades españolas es evidente (De Miguel, 2002b). El problema fundamental es averiguar por qué cuatro de cada cinco estudiantes de doctorado nunca terminan los estudios que deseaban realizar. Quizás la pregunta sea al revés ¿por qué se matricularon en doctorado si realmente no querían ser doctores? Las hipótesis son múltiples. Una razón es el mercado de trabajo que absorbe nuevos licenciados/as de forma lenta, con lo que una forma de evitar el paro es simplemente seguir estudiando (hacia un master o doctorado). Otra explicación relacionada, es que el doctorado sea una forma de conseguir un sueldo en forma de beca de personal investigador durante cuatro años. Solamente una minoría accede a esa beca, pero para esas personas es una salida airosa a la dificultad de inserción laboral. No son necesariamente «vocaciones investigadoras» sino candidatos/as a un salario bajo. La Universidad absorbe al 55\% de los/as investigadores en el país, pero no les garantiza recursos para realizar investigación (sólo cuenta con el $30 \%$ de recursos de I+D).

Matricularse en el doctorado es también una forma de encontrar empleo, a través de contactos personales. Unos/as cuantos terminan dando clase como profesores asociados o ayudantes, o en situaciones aún más precarias. A veces el sistema selecciona a los/as más inteligentes, otras veces a los más dóciles o con una mayor necesidad económica. Los/as pocos que tienen vocación investigadora se les diluye con la precariedad. Para personas de fuera de la capital (donde está su universidad) seguir estudiando - hacia el doctoradoes una forma de retrasar su posible vuelta al pueblo o a su pequeña ciudad de origen. Es así una forma de evitar la movilidad geográfica. La tendencia a permanecer en la misma ciudad donde se estudió es considerable. En casos extremos es una forma de alargar la juventud, una especie de «síndrome de Peter Pan»: no se casan, no se van de casa, no crean una familia, no tienen hijos/as, alargan la juventud, sin dramatizar la falta de inserción en el mercado de trabajo, o la falta de motivación por crear una familia. Ambos factores 
aparecen relacionados. No conviene echar la culpa a la víctima: los/as que más sufren esta estructura son los/as propios estudiantes de doctorado y nuevos doctores. En todos los casos, matricularse en el doctorado es una forma de hacer algo - estudiar - para lo que ellos/as ya están acostumbrados y preparados. Es posible que en algún otro caso la motivación responda a promesas falsas de algunos programas de doctorado. Esa posibilidad es más probable en programas de master que no analizamos aquî ${ }^{31}$.

Llama la atención el fracaso de los/as estudiantes en España, específicamente la cantidad de personas que aprueban los cursos de doctorado pero no consiguen realizar la tesis doctoral. Quizás muchos programas de doctorado sean poco motivantes, y muchos profesores de doctorado no sean realmente investigadores. Profesores que no investigan difícilmente pueden enseñar a investigar. Otra explicación de la falta de éxito puede ser que cada vez más personas de clases bajas se apuntan al doctorado, también más mujeres. Dadas las condiciones económicas quizás sobreviven menos tiempo en esos programas de estudio. Cada vez hay más mujeres en los programas de doctorado, pero las mujeres escogen programas menos exitosos (en las áreas de humanidades y ciencias sociales) o es al revés: los programas menos exitosos lo son por que se incorporan más mujeres. Las relaciones causales seguramente se producen en ambas direcciones. ¿El que los estudiantes de doctorado sean mujeres y sus directores de tesis doctorales sean varones puede explicar el fracaso? Otra explicación (parcial) es que quizás sean los extranjeros, que cada vez hay más, los que no terminan el doctorado. Son hipótesis que convendría demostrar, para las que no tenemos datos suficientes.

El sistema analizado globalmente parece bastante irracional y nada planificado. Si se observan las diferencias existentes por Comunidades Autónomas estos problemas son aún mayores. La productividad de nuevos doctores es una tasa que varía 25 veces entre unas Comunidades Autónomas y otras ${ }^{32}$. Es cierto que las diferencias en el sector de I+D son grandes (de unas ocho veces) pero no tanto como la producción de nuevos doctores. La Universidad no puede contratar a todos los investigadores (da trabajo a algo más de la mitad, el 55\%) así que en las regiones más desarrolladas los nuevos titulados «doctores» son absorbidos crecientemente por instituciones externas a la Universidad. Pero la desigualdad de investigadores en la Universidad según las Comunidades Autónomas siguen siendo de más del triple (3,4 veces). Muchas de esas diferencias reflejan las desigualdades de desarrollo económico de las Comunidades Autónomas españolas, que de forma global son del doble $(2,1$ veces en el PIB per capita). La Universidad - y el doctorado- en vez de ser

${ }^{31}$ No hay datos en España para analizar los programas de master ni la producción de personas con esa titulación no homogénea. Estamos ya realizando una investigación.

${ }^{32}$ No existe un consenso sobre si las Comunidades Autonomas deberían producir proporcionalmente el mismo número (o parecido) de doctores. Una tasa similar podría calcularse en relación al número de estudiantes universitarios, o bien respecto del número de estudiantes que empiezan el doctorado, o mejor aún la población total de la Comunidad Autónoma. Nada obliga a que las tasas sean idénticas, pero al menos que no haya diferencias enormes (mas de tres veces, por ejemplo, similar a las diferencias de PIB). 
un factor de igualacion es un factor de desequilibrio regional preocupante ${ }^{33}$. El sector público, que es mayoritario en doctorado, debería de utilizarse con objetivos de reducir las diferencias de desarrollo regionales. Pero no es así, sino que además la descentralización autonómica produce un incremento de las desigualdades. Las diferencias de 25 veces en la producción de doctores es un factor que debe llevar a una reflexión sobre los objetivos del doctorado en España. La pregunta de si sobran ofaltan doctores en España debe de reelaborarse incluyendo las diferencias entre las 17 Comunidades Autónomas. Los objetivos futuros para mejorar este sector supone varias tareas. Tras el presente estudio nosotros resumimos esas tareas posibles en siete:

1. Una tarea primordial del Estado sería producir un conjunto de datos fiables bien estructurado, a nivel nacional y por Comunidades Autónomas. Se necesitan datos por cursos, edades, procedencia, y causas de abandono, retraso en terminar los estudios de doctorado, o fracaso, situación económica e inserción en el mercado laboral. Se requiere saber cómo se mantienen los/as estudiantes, y sus objetivos familiares y laborales.

2. El doctorado no puede ser unos estudios indisciplinados, con pocos exámenes, y sin una dedicación clara del profesorado. Se requiere tender hacia unos estudios reglados, en horarios universitarios normales (de mañana), que garanticen la dedicación exclusiva del alumnado y profesorado, y que realmente enseñen a investigar. Pero esto sólo puede lograrse con un sistema de becas y ayudas económicas que permitan a los/as estudiantes de doctorado estudiar con dedicación exclusiva.

3. Hay que lograr que la mayoría de estudiantes que empieza el doctorado termine los estudios obteniendo el título de doctor. La experiencia es que la selección más estricta de estudiantes no ha logrado que terminen más, sino lo contrario. El éxito no está tanto en la selección, sino en la organización racional de los recursos.

4. Hay que asegurar que los/as estudiantes de doctorado aprendan a investigar, con profesores que realmente investigan. Hay que conseguir no sólo elevar la calidad de las tesis doctorales, sino sobre todo que las personas que empiezan a investigar continúen luego investigando, tras la obtención del título de doctor. Es decir, que la tesis doctoral no debería ser la última investigación de esas personas. Un problema es pues la transición entre el título de doctor y una ocupación investigadora y no sólo docente, y cada vez más fuera de la Universidad.

5. Hay que intentar que los programas de doctorado no sean programas de formación del personal propio de cada universidad. La situación actual

${ }^{33}$ Estamos de acuerdo con Juan A. Vázquez (presidente de la Conferencia de Rectores de las Universidades Españolas CRUE, y rector de la Universidad de Oviedo) en su artículo «No olviden la Universidad» (2004). 
supone problemas éticos considerables, y un nivel de endogamia académica elevado. Una solución es que los doctores se produzcan en unos pocos centros de excelencia, que luego empiecen a trabajar en otras instituciones. Eso llevaría a una estructura en que un conjunto de universidades no tuviese programas de doctorado, una especie de diversificación entre colleges y universidades. Pero además habría que buscar un equilibrio territorial (por Comunidades Autónomas).

6. Es aconsejable organizar un nivel intermedio -de master-en los programa de doctorado, que sirva para titular a personas que no desean realizar una tesis doctoral, o que simplemente no alcanzan la destreza suficiente para investigar. Estos programas de master, regulares, pueden organizarse legítimamente como programas de formación terminales. Los programas actuales de master en España -casi todos ellos creados sin condiciones académicas suficientes, y más bien como negocio- deben renunciar a utilizar ese título oficial, sustituyéndolo por otra titulación (como «diploma» 0 «postgrado»).

7. Se requiere investigar sobre el doctorado y sobre los procesos de investigación. En España, la falta de estudios científicos serios (independientes) sobre la organización de la Universidad, y sobre las titulaciones, es llamativa. Una razón es la carencia de datos, pero otra es que sencillamente no hay científicos sociales dedicados al tema. No existen estudios que comparen el sector de I+D fuera de la Universidad con el interno. Faltan investigaciones comparando la realidad de las 17 Comunidades Autónomas, y si se produce o no un proceso de convergencia. Según nuestra propia experiencia, el control gremial y el rechazo institucional contra la realización de este tipo de estudios es enorme. Eso explica, en parte, la falta de investigación empírica sobre la investigación y el doctorado. Hay que ver si el nuevo Ministerio de Educación y Ciencia (2004-2008) y el Gobierno socialista es capaz de solucionar estos siete problemas capitales.

\section{REFERENCIAS}

CONSEJO DE COORDINACIÓN UNIVERSITARIA (2002): Plan Nacional de Evaluación de la Calidad de las Universidades: Informe Global 1996-2000, Madrid: Consejo de Coordinación Universitaria, $150 \mathrm{pp}$.

EuROSTAT (2002): Yearbook 2002: The Statistical Guide to Europe. Data 1990-2000, Luxemburgo: Eurostat, $456 \mathrm{pp}$.

Fundación Santander Central Hispano (ED.): La Universidad en la sociedad del siglo XXI Madrid: Fondo de Cultura Economica, 304 pp.

De Miguel, Jesús M. (2002a): «Fundación Santander Central Hispano ed., La Universidad en la sociedad del siglo XXI» Revista Española de Investigaciones Sociologicas 99, pp. 254-268.

DE Miguel, Jesús M. (2002b): «Relación entre gasto y calidad en las universidades» Revista Española de Investigaciones Sociológicas 99, pp. 179-188. 
DE Miguel, Jesús M. (2003a): «Política de Universidad: Escenarios futuros» Revista de Estudios Políticos 122 (octubre-diciembre 2003), pp. 33-72.

De Miguel, Jesús M. (2003b): Situación de España en el Proceso de Bolonia según el Informe Trends 2003 (para la reunión de Berlín, septiembre 2003), 6 pp.

De Miguel, Jesús M. (2004a): El Proceso de Bolonia: ¿Hacia dónde va Europa? Barcelona: GRS, Universidad de Barcelona, 22 pp.

DE Miguel, Jesús M. (2004b): La ley catalana de universidades 2003 (Barcelona: Universidad de Barcelona, 377 pp. Actualmente en prensa, en Gestión y Análisis de Políticas Públicas.

De Miguel, Jesús M. (2004c): Universidad y democracia Cádiz: Premio de Ciencias Sociales Cortes de Cádiz, Ayuntamiento de Cádiz, 291 pp.

De Miguel, Jesús M. (en prensa): «La Ley catalana de Universidades 2003», 37 pp.

De Miguel, Jesús M. y Bernabe SARABia Heydrich (2003): «La Universidad española en un mundo globalizado: Los recursos» Revista Española de Investigaciones Sociológicas 102 (abril-junio 2003), pp. 207-259

De Miguel, Jesús M., CAïs, Jordi y VAQuera, Elizabeth (2000): Excelencia: Calidad de las universidades españolas, Madrid: Centro de Investigaciones Sociológicas, $506 \mathrm{pp}$.

De Miguel, Jesús M., CAïs, Jordi y VAQuera, Elizabeth (2003): Calidad de las universidades españolas y sistema universitario de las Comunidades Autónomas, Barcelona: Universidad de Barcelona, $91 \mathrm{pp}$.

De Miguel, Jesús M., Ponce de León, O. G. y Echavarren, J. M. (1999): «Investigación de la investigación social» Empiria: Revista de Metodología de Ciencias Sociales 2, pp. 169-214.

Ministerio de EduCACión, Cultura y DePORTE (2003): La integración del sistema universitario español en el Espacio Europea de Enseñanza Superior: Documento-marco Madrid: MECD, febrero 2003, 22 pp.

PÉREZ DíAZ, Víctor (2003): «Carácter y evolución de la Universidad española» Claves de Razón Práctica 136 (octubre 2003), pp. 22-29.

Pérez Díaz, Víctor (2004): «La reforma de la Universidad española»Claves de Razón Práctica 139 (enero-febrero 2004), pp. 18-25.

PÉrez DiAz, Víctor y Rodriguez Juan C. (2001): Educación superior y futuro de España Madrid: Fundación Santillana, 470 pp.

SARABIA, Bernabé y DE Miguel, Jesús M.: «La Universidad española en un mundo globalizado: Los resultados» Revista Española de Investigaciones Sociológicas (2004).

SMALlWOOD, Scott (2003): «American women surpass men in earning doctorates» The Chronicle of Higher Education (12 diciembre 2003), p. A10.

VAquera, Elizabeth G. y DE Miguel, Jesús M.: «Mujeres en la torre de marfil: Feminización de la Universidad española» Gestión y Análisis de Políticas Públicas 22 (septiembre-diciembre 2001), pp. 77-94.

VÁzqUEZ, JUAN A. (2004): «No olviden la Universidad» El País (26 enero 2004), p. 31.

\section{RESUMEN}

Por primera vez en España se analizan las necesidades de doctores (graduados de tercer ciclo universitario), estudiando la evolución seguida en la última década, y comparando con otros países especialmente con Estados Unidos y la Unión Europea. En España las tasas de estudiantes de doctorado y de producción de doctores son ele- 
vadas, al contrario de lo que sugieren los indicadores de $\mathrm{I}+\mathrm{D}$ que son bajos. Todas las universidades españolas - públicas y privadas - producen doctores; además hay programas de doctorado en la mayoría de los Departamentos. El sistema se autorregula más bien a la salida que a la entrada del doctorado, aunque lo hace de forma imperfecta. Los programas son un sistema de formación de personal docente propio. La proporción de estudiantes que empiezan el doctorado y no lo terminan es elevada: unas tres cuartas partes. La bolsa de doctores sin posibilidades de integrarse en el sistema universitario como docentes o investigadores es cada vez mayor. Las diferencias regionales son grandes. En España falta una política de doctorado. La carencia de datos fiables y detallados es un primer problema que habría que resolver. El artículo ha supuesto una colaboración especial entre Jesús M. de Miguel (Universidad de Barcelona), Bernabé Sarabia Heydrich (Universidad Pública de Navarra), Elizabeth G. Vaquera (The University of Pennsylvania, Filadelfia, Estados Unidos), y Haizam Amirah (Real Instituto Elcano de Estudios Internacionales y Estratégicos, Madrid).

\section{ABSTRACT}

This paper studies, for the first time in Spain, the need of doctorates (Doctor in Spanish, equivalent to $\mathrm{PhD}$ ), looking at the evolution of rates during the last decade, and comparing to other countries, especially United States. In Spain the rates of doctoral students and of new doctorates are high, contrary what low $R+D$ statistics suggest. All Spanish universities - both public and private- have doctoral programs, as well as the majority of Departments. The system is self controlled, more at the production of doctoral degrees conferred than at the incoming classes, but imperfectly. The proportion of drop outs, or students than never get the doctoral degrees, is quite high: more than $75 \%$. Doctorate in Spain is mainly a training program for teachers within the same university. The numbers of doctorates without employment as teachers or researchers in an educational institution is growing. Regional differences are also high. The Spanish university system lacks a doctoral policy. The lack of reliable data is the first problem to be resolved. This paper was undertaken as a special collaborative effort of the GRS (Sociological Research Group, at the University of Barcelona) between professor Jesús M. de Miguel (University of Barcelona, Spain), professor Bernabé Sarabia Heydrich (Public University of Navarre, Spain), Elizabeth G. Vaquera (The University of Pennsylvania, Philadelphia, United States), y Haizam Amirah (Elcano Royal Institute for Strategic and International Studies, Madrid). 